\title{
THE BELIEF IN MERITOCRACY PREDICT WELL-BEING OF LOW STATUS COLLEGE STUDENTS WHEN PERCEIVING DISCRIMINATION?
}

\author{
A Dissertation \\ Presented to \\ the Faculty of the Graduate School \\ at the University of Missouri-Columbia \\ In Partial Fulfillment \\ of the Requirements for the Degree \\ Doctor of Philosophy \\ by \\ XINTING ZHAO \\ Dr. Roberta Scholes, Dissertation Supervisor \\ DECEMBER 2019
}


(C) Copyright by Xinting Zhao 2019

All Rights Reserved 
The undersigned, appointed by the dean of the Graduate School, have examined the dissertation entitled

DOES THE BELIEF IN MERITOCRACY PREDICT WELL-BEING OF LOW STATUS COLLEGE STUDENTS WHEN PERCEIVING DISCRIMINATION?

presented by Xinting Zhao, a candidate for the degree of doctor of philosophy, and hereby certify that, in their opinion, it is worthy of acceptance.

Professor Roberta Scholes

Professor David Bergin

Professor Ze Wang

Professor Lori Thombs 


\section{ACKNOWLEDGEMENTS}

My sincere thanks are given to Dr. Roberta Scholes, my dissertation advisor, for her patient advice and guidance throughout my period of study. All of the members of my dissertation committee, including Dr. Roberta Scholes, Dr. Steve Osterlind, Dr. David Bergin, Dr. Ze Wang, and Dr. Lori Thombs helped to teach, challenge, and encourage me throughout my study as well as the development and completion of this dissertation and for this I offer my deepest and heartfelt thanks. I could not have completed my studies without their support, patient and understanding.

I am also lucky to have support and encouragement from my Masters advisor, Yan $\mathrm{Xu}$ in Beijing Normal University and her graduate advisees. I not only received help with recruitment of participants and search for Chinese research literature, I am accepted and supported as a family member. They listened to my confusion and frustration despite the time difference. I highly value the friendship of Dr. Fang Wang, Dr. Zhuyuan Liang, Dr. Shuyue Zhang, Dr. Su Tao and Peng Zhou. Decades of separation and the Pacific Ocean cannot change our closeness.

Special thanks to a true friend, Dr. Cindy Ann Smith. She is like a lighthouse encouraging me to move forward in the dark. She leads and guides me with love and patience. She believed in me even when I did not. What she offers is far beyond friendship. I learned so much from her wisdom, kindness, humor, toughness and perseverance. I'm so proud that she is the godmother of my children.

When I had medical problems after the birth of my second son, my parents, Jiaxun Zhao and Mingyi Gong, came to the US to help me despite their poor health. My mother 
had two recurrences of liver cancer after she returned to China. Their love and care makes me strong and keeps me continually working towards my goals.

Happy 20-year-anniversary to my husband Peng Zhuang. All of these years you love and support me, trust me on whatever I want to do, and tolerate me on bad days.

I appreciate my sons, Chuting and Chuyang Zhuang. I have learned to be patient, calm, a multi-tasker, better time management and emotional control, through raising them. I grew up with them again, and have had a second chance to see the complexities in my childhood, and become a better person in the process. 


\section{TABLE OF CONTENTS}

ACKNOWLEDGEMENTS $\quad$ ii

LIST OF FIGURES vii

LIST OF TABLES viii

$\begin{array}{ll}\text { ABSTRACT } & \text { ix }\end{array}$

CHAPTER 1 INTRODUCTION 1

Ma's story 1

Purpose of the Study $\quad 4$

$\begin{array}{ll}\text { Research Questions } & 6\end{array}$

Significance of the Study $\quad 9$

CHAPTER 2 LITERATURE REVIEW 11

$\begin{array}{ll}\text { Overview } & 11\end{array}$

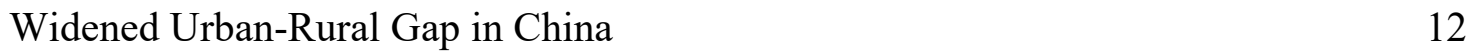

Perceived Discrimination of Low Status Students 15

Self-esteem, Perceived Control, School belongingness as Consequences of Perceived

$\begin{array}{ll}\text { Discrimination } & 17\end{array}$

Coping Mechanisms and Support Attempted by Universities 19

$\begin{array}{ll}\text { Belief in Meritocracy } & 21\end{array}$ 
The belief in meritocracy and discrimination

Meritocracy in School

School Belongingness

CHAPTER 3 METHODS

Participants and procedure

Measures

Factor Analysis

Analysis

CHAPTER 4 RESULTS

Research Question 1

Research question 2

Research Question 3

Discrimination

Belief in Meritocracy as Protective Factor

Limitations and Directions for Future Research 
Appendix D, IRB Approval Document 


\section{LIST OF FIGURES}

Figure 1. Theoretical Model

Figure 2. Urban-rural income ratio 1978-2006 (Report of the fourth meeting of the

Eleventh National People's Congress, 2007).

Figure 3. Confirmatory factor analysis for self-esteem, meritocracy belief, perceived control and school belongings.

Figure 4 Path analysis of consequences of perceived discrimination

Figure 5. Distribution of imputed meritocracy belief

Figure 6. Group means analysis for belief in meritocracy

Figure 7. Path analysis of influence of meritocracy belief

Figure 8. Path analysis of beneficial of meritocracy belief 


\section{LIST OF TABLES}

Table 1. Social Economic Status Locally and Nationally 32

Table 2 . Exploratory Factor Analysis for Belief in Meritocracy Scale 40

Table 3. Response of Perceived Discrimination. Percentage in Parenthesis 47

Table 4. Means and SD of Perceived Discrimination 47

Table 5. Response of Awareness of Discrimination. Percentage in Parenthesis $\quad 50$

Table 6. Means and SD of Awareness of Discrimination 50 
DOES THE BELIEF IN MERITOCRACY PREDICT WELL-BEING OF LOW STATUS

COLLEGE STUDENTS WHEN PERCEIVING DISCRIMINATION?

XINTING ZHAO

Dr. Roberta Scholes, Dissertation Supervisor

\begin{abstract}
Students in Chinese universities from lower social or economic classes may be at risk of peer discrimination with negative physical and psychological effects; they may experience poor academic, social and career outcomes. Resources for supportive counseling are unlikely; therefore, self-coping skills are essential. Student participant survey data from three Chinese universities were used to evaluate whether meritocracy belief, a coping mechanism deeply rooted in Chinese culture, protects the self-esteem, health, and school connectedness of students at risk. Structural Equation Modeling (SEM) was used to examine meritocracy beliefs of students from high or low status. Comparison groups of students, high socioeconomic status (SES) vs. low SES, urban vs. rural, and male vs. female were examined regarding factors relevant to discrimination. Students with high or low levels of meritocracy belief were compared for differences in self-esteem, school belongings, perception of control and victim blame. Overall a belief in meritocracy was found to support students' self-esteem and sense of school belonging for both high- and low- status students. Perception of control was a mediator. Limitations and implications for practice and future research are discussed.
\end{abstract}




\section{Chapter 1}

\section{INTRODUCTION}

\section{Ma's story}

Jiajue Ma, a biology student at Yunnan University since 2000, received the death penalty in June, 2004 for murdering his four roommates (Jin, 2004). In his confession, Ma stated that he felt isolated and ridiculed because he was poor, which contributed to differences in behavior and dress from his peers. However, Ma seemed to direct his rage toward those in his own social group. Three of his four victims were also poor students from rural areas similar to Jiajue Ma.

Ma's case roused a greater focus on the mental health of students with financial stress, especially those from rural areas (Ma \& Wang, 2006). The source of Ma's tragedy may be due to elements of his own personality and darkness. However, his rage against his feeling of discrimination was also likely a contributing factor. Although most students fortunately do not react in the extreme fashion that Ma did, Chinese students from rural backgrounds often have difficulty fitting into university life. According to the Chinese Academy of Social Science (2013), they are less prepared for the College Entrance Exam (CEE), have less chance of gaining college admission, and are less likely to fit in academically or socially. Because more than half of the population in China currently live in rural areas, this problem potentially has significant negative social and economic impacts for the society overall. Therefore, it is important to search for realistic solutions to the problem. 
Universities have tried to implement different supports for students from poor/rural backgrounds. Some colleges encourage poor/rural students to build their own student associations to get better social support (Sun \& Zhang, 2015). Others encourage students to utilize psychological consultation services (He, 2011; Qi, 2005; Zhang, 2004). However, the Chinese culture generally does not encourage people to seek social support or otherwise be open and expressive of their feelings. Moreover, although all colleges have a student counseling center, their population is often more than 50,000 students, making it difficult for the students to access individual counseling services $(\mathrm{Wu}$, 2016). In fact, less than $4 \%$ of the college students actually utilized the services of the student counseling center according to the reports of Zhang and Xie (2009) and Wang (2011). In addition, the magazine, Paper (2016) pointed out that even in colleges in Shanghai, the most developed city in China, the proportion of the population who utilized counseling services was only around 1\%. Recently, many colleges have begun to include basic psychology courses within their curriculum with an emphasis on positive psychology as an alternative resource. However, the outcome of this nationwide project is yet unknown since it has only been in effect since January 2015.

Positive psychology may not be readily accepted, particularly by rural college students who may be most in need of psychological support, due to the relatively recent (less than fifty years) introduction of Western styled positive psychology into Chinese culture (Zhang \& Xie,2009). Because of this, focusing on beliefs within traditional Chinese culture emphasizing meritocracy, the belief that everyone will get what they deserve by hard work, may be more useful (Wiederkehr et al., 2015). This deep rooted, foundational belief in meritocracy within the Chinese culture encourages people to 
persevere in hard work to obtain a brighter future. Traditionally this was the view which motivated people to study diligently for at least 10 years in order to pass the government exam so they could be certified as a government officer. Therefore, helping rural students to refocus on a foundational belief in meritocracy may provide them with a culturally appropriate method of coping in order to overcome the barriers as a poor/rural college student in China.

For this purpose, this study investigated if a belief in meritocracy could be effective as a coping mechanism for rural college students in China to protect their well-being. The increase of this belief, deeply rooted in Chinese culture, which focuses on the view that school success is based on will and hard work may allow lower status Chinese college students to improve their sense of well-being via perceived control, and allow them to maintain more positive feelings when facing discrimination (Wiederkehr et al., 2015). Although it is important to understand ways to support college students from rural areas, all students of lower status may also benefit from a stronger belief in meritocracy. Lower status students are defined, for the purpose of this study by two criteria, socialeconomic status (SES) and their family origin (urban vs. rural area). A third criterion, the gender, will also be discussed.

I compared students with a stronger belief in meritocracy to students with lower belief in meritocracy to understand if this difference is related to their perception of discrimination. Further, does this difference influence their level of perceived control, do they spend more time on their academic activities and do they feel a greater sense of belonging to their school, and have higher levels of self-esteem overall? I also wanted to understand if students with a strong belief in meritocracy have a relatively larger 
improvement in their academic performance as compared to their college admission scores. I also examined the phenomenon that victims of discrimination tend to distance themselves from their social group (victim blame) as Ma did when he turned his rage upon other students who were also from rural areas.

Multiple group comparison methods were used to examine the group differences among students of perceived discrimination, perceived control, level of self-esteem, and belongingness to school. Also, a structural equation model (SEM) was used to test if the reported belief in meritocracy would benefit lower status students for self-esteem, and their perception of school belongingness through the mediation of perceived control when controlled for the level of discrimination. The remainder of this chapter will specifically discuss the purpose of the study, the research questions and provide a theoretical model of the research, ending with a discussion of the significance of the study.

\section{Purpose of the Study}

The main purpose of this study was to understand if the belief in meritocracy could help lower status students who feel they are facing discrimination. The concept of shame is prominent in eastern culture; students who have experiences which make them feel unfairly judged may feel too ashamed to seek help or even talk about it. In this case, having an internalized coping mechanism is very important when dealing with their experiences regarding discrimination. The belief in meritocracy has deep roots in Chinese culture which could make it a powerful tool to help protect student well-being.

Understanding more about how a belief in meritocracy may protect lower status students who experience perceived discrimination, might provide college teachers and 
faculties with information to better support students through meritocracy. Staff who work in the area of student well-being (i.e. counseling center, student center) may be able to use this information to support the development of student coping strategies.

The second purpose of this study is to more fully understand the ways in which low status Chinese college students perceive discrimination in order to allow universities to more fully support their students. Because the attitudes of higher status Chinese college students may necessarily influence their lower status peers, it is important to also understand the effect of this interaction on both groups. Specifically, I wanted to understand the situation of low status college students: do they perceive discrimination in their daily life? If so, is this discrimination targeted more to individuals or towards the group? As to the advantaged, higher status group of students, are they aware of discrimination felt by their disadvantaged peers? Do they contribute to the attitudes of prejudice without realizing it? Further, I wanted to understand the differences between the advantaged and disadvantaged student groups concerning their self-esteem, their perception of school belongingness, their perception of control and who or what they feel is to blame for the discrimination.

The phenomenon of discrimination needs to raise attention to both students and faculty members of Chinese colleges. This research will point out the situation of students experiencing discrimination and its consequences in college life and thus urge students and faculties to be more sensitive to discrimination and inspire future researches about discrimination.

The third purpose of the study was to more fully understand the concept of meritocracy. Specifically, what factors may predict a belief in meritocracy, such as 
parent education level or occupation. Alternately, could other role models, such as teachers or peers, influence meritocracy beliefs? By understanding how a belief in meritocracy may influence students, teachers and faculties could be more motivated to focus on this belief to support their students. Further, a more complete understanding of the contributing factors of a belief in meritocracy will make it easier to support students to deepen their belief in meritocracy.

\section{Research Questions}

Question 1: What level of discrimination do students who are enrolled in Chinese colleges perceive?

This is an important area to understand, particularly since China is primarily a country with citizens of a single race, and the majority have no religion, in contrast to a multicultural country such as the United States where there is a wide variance of race and religion among its citizens. These differences may make people who look different, such as with darker skin or different types of dress because of their religion, more vulnerable to discrimination. However, in China, it is more difficult to prejudge others by their appearance (other than gender). As a result, Chinese people may be more insensitive to discrimination in their daily life. For example, when a work position is advertised for applicants, the description may include the wording "male only." The language is not perceived as discriminatory by either the hiring manager or female workers. Because Chinese people do not tend to recognize discrimination, when a person who does feel offended and complains about a perceived slight, they are often seen as being overly sensitive. However, the discrimination is real, and it does real harm (Pascoe \& Smart Richman, 2009; Schmitt et al., 2014). Especially in colleges where most of the students 
start a new life away from their parents, they need to adjust to college life and focus on study, so that they can graduate and be successful in the future. If they experience discrimination with negative consequences, it can damage their future prospects. Therefore, this study sought to answer the following sub-questions for Question 1:

1. What demographic factors predict perceptions of discrimination in Chinese college students?

2. What proportion of students are aware of discrimination?

3. Does perceived discrimination predict self-esteem, perceptions of control, belief in meritocracy, school belonging and victim blame?

Question 2: What is the level of college students' belief in meritocracy?

The belief in meritocracy is deeply rooted in Chinese culture yet has recently been challenged. The belief in meritocracy emphasizes personal effort and thus it helps to focus more on academic goals and less on distractions (Laurin, Fitzsimons, \& Kay, 2011). This study aimed to learn more about the belief in meritocracy, what factors contribute to it and how it contributes to students' college life. Detailed research questions are:

1. What demographic factors predict the belief in meritocracy?

2. Does belief in meritocracy predict self-esteem, perceptions of control, and school belongingness while controlling for perceptions of discrimination?

Question 3: Does belief in meritocracy predict students' belongingness to school and their self-esteem via perceived control while controlling for perceived discrimination? 
Research has demonstrated that the belief in meritocracy is beneficial (for example, Laurin, 2011; McCoy, etc. 2013). But it is not clear if the benefits are consistent throughout Chinese society; therefore, multigroup analysis will be conducted:

1. Students from urban areas vs from rural areas

2. Students with high SES vs low SES, and

3. Male vs female students

Past research has demonstrated that by improving perceived control, belief in meritocracy protects lower status group members by increasing their self-esteem and improving their in health when experiencing perceived discrimination (McCoy et al., 2013). Besides the benefit to mental and physical health, a belief in meritocracy may also support a sense of belonging towards their college. Because academic motivation is a big factor of influence for school belongingness (see Allen and Kern, 2017), the belief in meritocracy encourages students to put more effort into studying and thus they are expected to have better academic performance, which will in turn improve their academic motivation. Moreover, if the student has a strong sense of academic success and future career attainment as their primary goals in college, he or she is less likely to be distracted by discrimination. The reason I do not add academic performance in the model is because for most of the students the academic score is self-reported, which could make the validity of the information questionable. A graphic representation of this theoretical model is presented in Figure 1. 


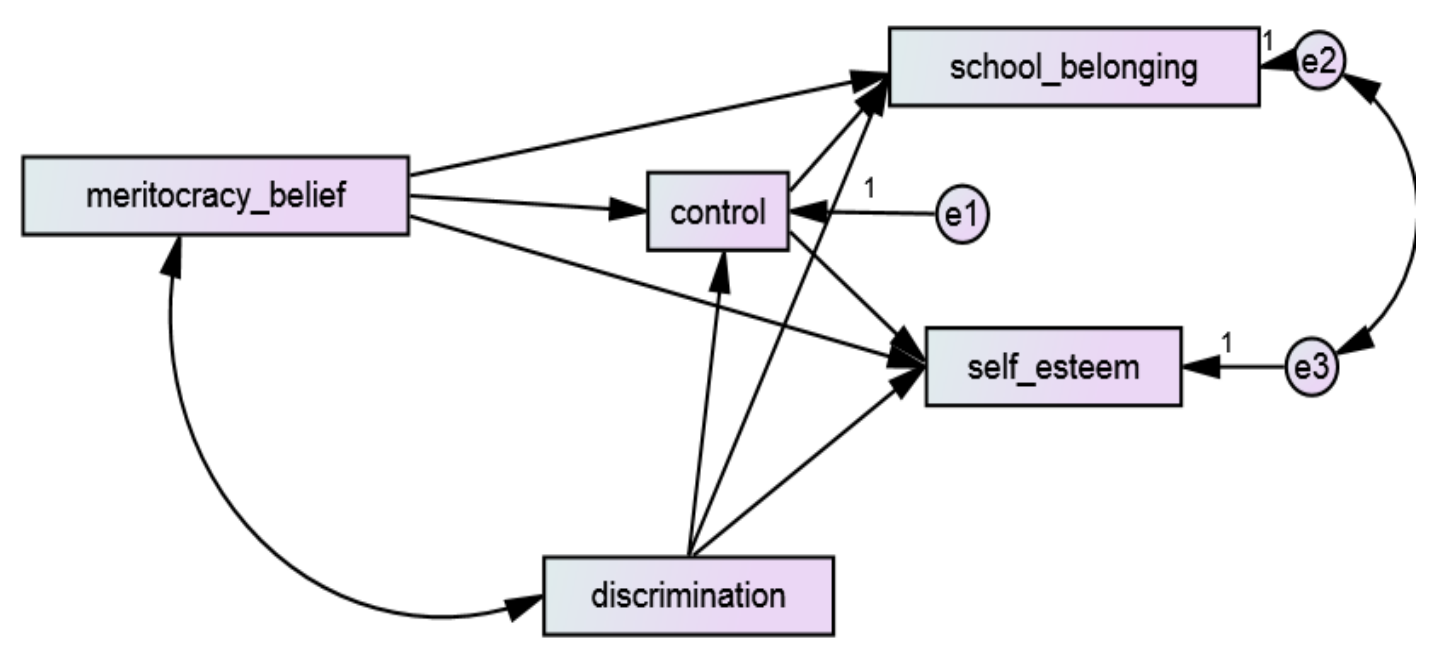

Figure 1. Theoretical Model

\section{Significance of the Study}

The aim of this study was to raise awareness of existing discrimination among students on Chinese college campuses. It is important to better understand which variables contribute to the problem in order to understand specific groups of students who perceive discrimination from other groups of students. Unlike the mindfulness method which requires the student to learn and accept, or counseling therapy which requires large amounts of college resources that are unlikely to be available, instructing and encouraging the students in the belief in meritocracy may provide an internal support for college students. If under certain conditions the belief in meritocracy can benefit the lower status college students, this could be a practical solution as it builds on supports (i.e. existing psychology classes) already in place. Future studies could examine relevant causal variables and patterns. 
Students who have a sense of belonging or connectedness to their school environment are more likely to persist to graduation and may be less likely to exhibit high risk behaviors and are more likely to have a healthy self-view (Karcher, 2004). This research also included the sense of school belonging into the grid of discrimination research. For most of the students, entering college is the first time they are living away from their families, and having a sense of belonging is important to their mental and physical health. Although a lack of school belonging may not be seen as a direct result of discrimination (see Allen and Kern, 2017), I argue that school belonging is affected by perceived discrimination and it can be supported by the belief in meritocracy. 


\section{Chapter 2}

\section{LITERATURE REVIEW}

\section{Overview}

A successful college experience is often times difficult to achieve. This is particularly true for certain groups of students in China who may be disadvantaged and less prepared for college due to lower status factors such as living and attending school in a rural area and/or their family's low economic status. As they make the transition to college life, they need to adjust to living independently from their families as well as to be able to blend in with their peers, feel they belong to the university community and be academically successful. All students experience transitional issues; however, students from this lower status group might have an especially hard time making the adjustment and be vulnerable to discrimination and bullying. All of these issues may contribute to a higher level of mental stress as reported by Ma and Wang (2006).

The purpose of this study was to understand more about students in lower class groups, as described above, who are facing discrimination in Chinese colleges. More importantly, the belief in meritocracy is presented as a protective coping method for students in lower classes to combat discrimination. This is an important issue, because as a developing country, significant numbers of Chinese citizens are from rural areas or under financial stress, and discrimination may hinder their academic success and emotional well-being when they attend university. Meritocracy is a foundational belief system within the Chinese culture which encourages people to work hard over an extended period of time to achieve a better future. 
Utilizing this belief in meritocracy as the foundation of a supportive service may provide an important tool for Chinese universities to support their students of lower status and provide a more inclusive atmosphere, which in turn, may promote a more positive learning environment for all students. In this chapter, I will discuss the following six topics. First, I will discuss the widening urban-rural gap in China including the historical context, which may leave some students more vulnerable to discrimination (Mossakowski, 2003), with disturbing consequences depending on how students perceive this discrimination. Second, I will discuss the effectiveness of coping methods for perceived discrimination, with a more focused discussion of those currently attempted by Chinese universities (Qi, 2005). Third, I will explain the concept of meritocracy including theoretical foundations and the relationship to traditional Chinese culture (McCoy et al., 2013). Fourth, I will review the available research regarding meritocracy, particularly that which investigates the advantages and disadvantages of holding meritocracy as a worldview relevant to a discussion of meritocracy belief in academic settings. Finally, I will conclude with a discussion of school belongingness, including its importance to college students as a sense of security and the different factors which could be influenced as a result.

\section{Widened Urban-Rural Gap in China}

There is an ever increasing gap between the urban and rural populations in China, created by a difference of opportunities between urban and rural citizens. These differences may contribute to an increase in financial stress. Because urban jobs provide higher incomes than rural jobs, some people will travel to urban areas to work, leaving their children in the care of grandparents. Additionally, more rural students are dropping 
out of high school. Some scholars believe these changes are among the underlying cause of discrimination among Chinese citizens (Jin, 2004, Ma \& Wang, 2006). In order to fully understand the changes which contribute to this widening gap, it is important to understand the historical context of Chinese culture.

China existed as an agricultural country for thousands of years. Before the twentieth century, in feudal society, landowners, farmers and peasants were recognized as the foundation of society and were highly respected. In his book Master Guan, Zhong Guan (around $450 \mathrm{BC}$ ) discussed the prevalent social hierarchy during the era of the feudal dynasties. According to Zhong Guan (around 450 BC), landowners, farmers and peasants were socially ranked above engineers, craftsmen, merchants and businessmen. The only members of society with higher standing were government/military officers and the literati.

However, as the focus of the country shifted from agriculture to industry, society's perception of the value of rural agricultural workers diminished (Wang, 2012). Farmers and peasants were no longer viewed as the most productive; instead workers who utilized newly developed machines were viewed as more productive and forward thinking. Eventually those in rural farm areas were perceived in negative ways such as being unwilling to change or short-sighted. In addition, since peasants labored within the family unit, they did not live on a tight schedule. Thus, they were mocked as lazy and insular.

Industrialization has also contributed to the income difference between rural and urban workers, with a subsequent decrease in the standard of living among rural residents as compared to their urban counterparts, according to the Chinese Department of 
Agriculture (see figure 2, Report of the fourth meeting of the Eleventh National People's Congress, 2007). In 1985 urban residents earned almost twice as much as their rural counterparts and by 2006 this gap had further increased; the urban resident was earning more than 3 times as much as rural residents. This income disparity encourages yet another stereotypical view of rural dwellers by their urban counterparts as stingy and rustic, which may promote further discrimination.

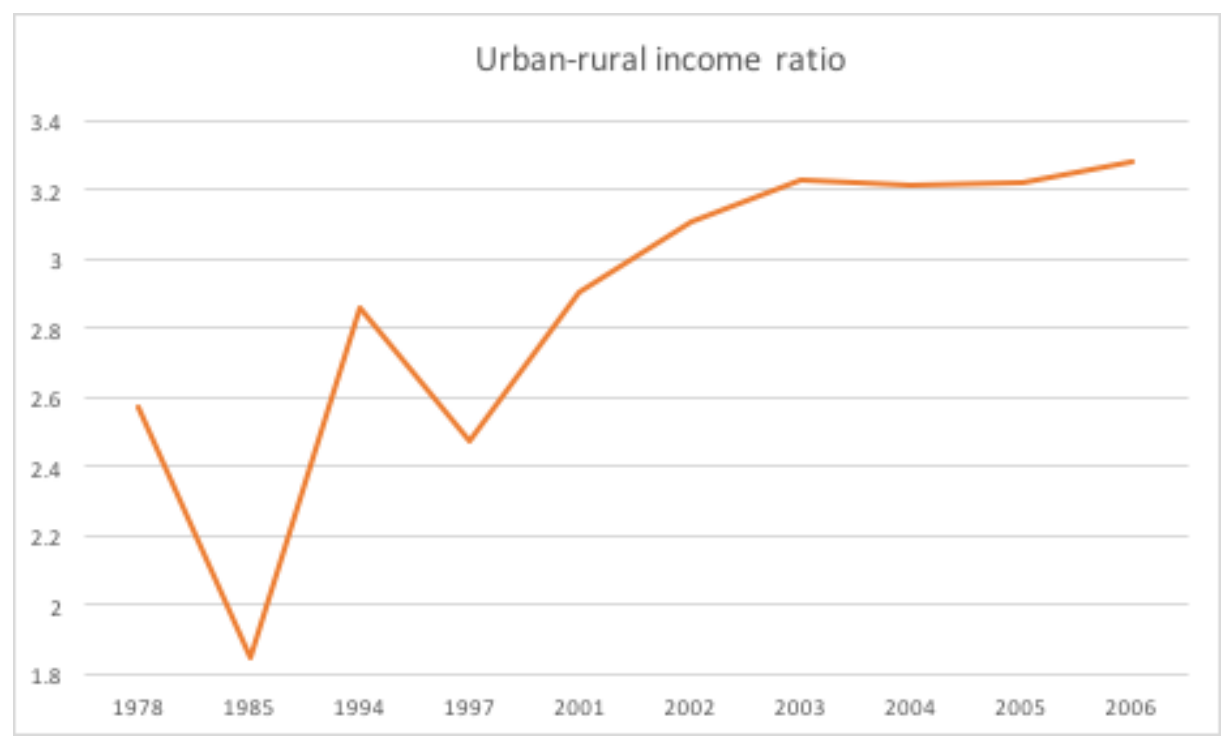

Figure 2. Urban-rural income ratio 1978-2006 (Report of the fourth meeting of the Eleventh National People's Congress, 2007).

This widening economic imbalance between urban and rural dwellers is likely to impact education. In China, the construction and operation of rural schools including teacher salaries are the responsibility of local governments with some financial support from central government (Liu \& Zhou, 1995). Therefore, schools in rural areas generally have lower teacher salaries and less resources for equipment, etc., often resulting in urban schools being able to attract more highly qualified, more experienced teachers. For example, in 2003, financial resources of rural public schools amounted to 
only $72.6 \%$ of available financial resources of their urban counterparts. Overall, it is difficult for rural areas to compete with urban areas to provide high quality learning environments often resulting in educational inequality (Qian \& Smyth, 2005).

China has a long history of $\mathrm{Ke} \mathrm{Ju}$, the system which allows ordinary citizens to apply for the opportunity to take certain exams and gain social status as government officers by their successful completion. This may mean years of hard study to prepare for these exams. Ke Ju began in 746 AD and continued for almost 1200 years until 1911, the end of the Qing Dynasty. Therefore, the tradition of knowledge changing fate is more than a motto in China. For thousands of years the Chinese people truly believed that intensive, focused study would result in a better life. However, the Chinese economic reform, which began in 1978, now offers many investment opportunities which could result in sudden wealth without years of hard work or education being required. One example of this is the sharp rise of property values; in some areas property values increased more than 10 times within one decade. Therefore, modern Chinese citizens might not embrace meritocracy ideology as strongly as their ancestors, because they may see these opportunities for investment as a better option than hard work. Because of this difference, I want to understand if Chinese college students still hold the belief in meritocracy, and if this belief might support their mental well-being.

\section{Perceived Discrimination of Low Status Students}

This wide economic gap between rural and urban residents is likely to foster strong stereotypical perceptions of rural students by their urban peers. These perceptions may give rise to negative attitudes toward minority groups of rural students, making them vulnerable to discrimination. Researchers have found that poor/rural college Chinese 
students reported experiencing perceived discrimination as individuals as well as a group (Chen, 2010; Jin, 2004; Long, 2003; Yang, 2004). The students felt the discrimination was usually due to their accent, manner of dress, poverty, less participation in social activities, lower level of self-esteem and lower level of background knowledge in art, science, speech, etc. (Chen, 2010; Jin, 2004; Long, 2003; Sun \& Zang, 2015; Yang, 2004). Besides the discrimination from their peers, students also face prejudice through the internet (Chen, 2010; Sun \& Zang, 2015). For example, the term "phoenix guy" which originated on the internet, refers to a college graduate from rural areas or a very poor family who used up all of the family resources to complete his higher education, and thus he (or she) must sacrifice starting his or her own family with a spouse to "pay back" the original family.

Multiple studies have sought to understand the mental health of lower status Chinese students in comparison to their peers. The majority of these studies were conducted from 2002-2005, shortly after the murder of Jiajue Ma, with a limited number of studies conducted more recently. The majority of the studies utilized self-report questionnaires such as: The Sixteen Personality Factor Questionnaire (16PF; Cattell et al., 1970) and the Symptoms Checking List (SCL-90; Derogatis et al., 1973) and other instruments, with similar findings. Overall, the findings suggested that as compared to their high status peers, low status students (who mainly reported difficulty due to financial stress) had significantly lower scores in self-esteem, higher scores in depression, anxiety, quality of interpersonal relationships and hostile factors (see in Chen, 2004; Chen, 2016; Chen et al., 2003; Han \& Wu, 2018; Kong et al., 2007; Li, 2002; Pan \& Xiao, 2014; Xu, 2001; Zhang ., 2011; Zheng, 2008; Zhou, 2009). In addition, within the low status group, 
female students scored significantly lower in self-esteem and higher in depression than their male peers (Chen, 2016; Pan \& Zhou, 2009; Zheng, 2008). Some studies also indicated a higher level of self-blame (Li, 2002; Zheng, 2008) and social withdrawal (Chen, 2004; Zheng, 2008). There is also evidence of students feeling less supported socially (Chen, 2004), and they were less likely to seek needed social support (Li, 2002;

Xiao, 2014) and overall, seemed to lack efficient coping skills (Chen, 2016; Xiao, 2014).

\section{Self-esteem, Perceived Control, School belongingness as Consequences of Perceived Discrimination}

Research indicates negative outcomes of discrimination including low self-esteem and a lack of psychological well-being (Major, Kaiser, \& McCoy, 2003; Major \& O’Brien, 2005; Mendes et al., 2008). Perceived discrimination influences mental health, including increased psychological distress and increased symptoms of depression (Williams \& Mohammed, 2009). Lowered self-esteem is the immediate reaction across different forms of rejection and discrimination (Schmader, Major \& Gramzow, 2001; Smart Richman \& Leary, 2009). Pascoe and Smart Richman (2009) analyzed 110 studies concerning discrimination and concluded that individuals exposed to discrimination had negative mental health outcomes such as depression, psychological distress, anxiety, and well-being. A larger size meta-analysis analyzing 328 studies conducted by Schmitt and colleagues (2014), examined experiments that manipulated perceptions of discrimination and revealed causal relationships between perceived discrimination and negative psychological outcomes such as self-esteem, depression, anxiety, psychological disease and life satisfaction with an effect size of -.25. 
Chinese researchers had similar results. For example, 1006 rural-to-urban immigrants to Beijing, China were queried regarding perceived discrimination which was found to significantly lower their perceived quality of life (Zhang et al., 2009). Xue, Lu, \& Liang (2008) examined the mental health of 1214 college students using the Symptom Checklist 90 (SCL-90) (Derogatis, 1973) comparing the differences between students from rural and urban areas. The university students from rural areas scored higher in anxiety, depression, interpersonal sensitivity, paranoia, and compulsion than the university students from urban areas. This study confirmed the results from similar studies conducted by He (2012), He and Zeng (2011), Qi (2005), Xin, Zhang, \& He (2012) and Zhang (2004). Studies comparing impoverished college students and non-impoverished college students found similar results of significantly lower scores on self-esteem, higher in anxiety, depression and interpersonal sensitivity (see in Chen, 2004; Chen, 2016; Chen et al., 2003; Han \& Wu, 2018; Kong et al., 2007; Li, 2002; Pan \& Zhou, 2009; Xiao, 2014; Xu, 2001; Zhang et al., 2011; Zheng, 2008). Because self-esteem is the key element of psychological well-being (Schmitt et al., 2014) and a strong predictor of subjective well-being (Kong et al., 2007), in this study self-esteem is included as a dependent variable.

Feeling less in control of their life is another consequence of perceived discrimination (Pascoe and Smart Richman, 2009; Schmitt et al., 2014). Lacking control leads directly to poor health habits and negative psychological well-being (Pascoe and Smart Richman, 2009). A sense of control is found to moderate the negative impact of perceived discrimination towards self-esteem (MaCoy et al., 2013). There was a similar finding (Han \& Wu, 2018) regarding Chinese college students; specifically for students with a 
low SES, a sense of control of their future would moderate the negative relationship between perceived pressure and subjective well-being. However, this effect was not found for Chinese students with a high SES. Students who indicated a strong sense of control for the future had a weaker negative correlation between perceived pressure and subjective well-being. This sense of control predicted subjective well-being for impoverished Chinese college students but not non-impoverished students (Kong et al., 2007). Therefore, in this study the perceived sense of control was used as a dependent variable as well as a mediator.

In the academic arena, experiencing discrimination is related to lower levels of academic success (Benner, Crosnoe \& Eccles, 2014; Benner \& Graham, 2011; Loeb \& Hurd, 2017; Schmader, Major \& Gramzow, 2001). Adolescents who report a perception of discrimination also report a perception of negative and unfair school climate which often leads to feelings of alienation (Benner, Crosnoe \& Eccles, 2014; Benner \& Granham, 2011). Unfortunately, in this study, the majority of universities who participated did not provide academic performance records for the students who were participating. However, I included student-reported effort and expected academic performance as dependent variables. In addition, I investigated school belonging as an outcome of perception of discrimination.

\section{Coping Mechanisms and Support Attempted by Universities}

Research within western cultures has suggested multiple coping mechanisms for perceived discrimination. Brown-Iannuzzi et al., (2014) suggested the trait of mindfulness could dampen the relationship between perceived discrimination and depressive symptoms. Mossakowski (2003) believed that having a sense of ethnic pride, 
involvement in ethnic practices, and cultural commitment to one's racial/ethnic group may protect mental health.

The majority of Chinese research has focused on social support when dealing with perceived discrimination by encouraging students to build their own associations or support groups and talk to their friends or instructors (Sun \& Zhang, 2015). Other researchers (Zhang et al., 2011) also demonstrated peer support to be a good coping method for students who struggle with financial stress. However, both Li (2002) and Xiao (2014) determined that low status college students were less likely to seek social support. In addition, impoverished students believed that adequate social and academic support was unavailable to them (Chen, 2004; Chen et al., 2003). There are studies which indicate students with low SES and/or from rural areas have less efficient coping skills (Chen, 2016; Xiao, 2014), which may negatively impact their ability to obtain the help they need.

At the same time, some research appears to place the blame on an oversensitivity of the disadvantaged group of students (for example, see Wu, Ma, \& Qi, 2012). Impoverished college students are more likely to blame themselves for their situation (Chen, 2014). These studies indicated that those who believe in a just world, particularly holding a view of meritocracy, often tend to be more likely to blame the victim (Correia, 2018; Major et al., 2007). Therefore, we need to also consider victim blame as part of the entire picture to better understand the coping style of Chinese college students.

Researchers (Xu, 2001) suggested that lectures and group- and individual- counseling significantly impacts the mental health of low status college students in a positive manner. There is evidence that an increasing number of professors and staff realize the 
psychological needs of their students and are becoming more willing to spend time talking with them. A survey (Wang \& Deng, 2006) indicated that $36 \%$ of poor students said they had discussed their anxiety with their instructors on a regular basis. However, as previously discussed, the counseling services in Chinese colleges are very low in number and generally not culturally acceptable. With heavy teaching, research and funding duties, teachers and professors are generally not capable of taking care of the emotional or mental health needs of their students. Most of the research conducted around Chinese college students noted that beliefs rooted in traditional Chinese culture are likely to be a useful support for students who struggle with perceived discrimination. As mentioned previously, a belief in meritocracy is deeply rooted in Chinese culture.

\section{Belief in Meritocracy}

The idea of meritocracy has received much attention since British sociologist Michael Young first coined the term in 1958. In particular, meritocracy -- the belief that success or achievement is based on individual merit and hard work -- has been recognized as an ideology that encourages moving to better status via self-striving and thus positively promote the concept of the "American Dream" (Sealy, 2010). Meritocracy has allowed low status group members to dream about improving their social status, economic class, and place in the hierarchy, implanting the ideology that everyone has a chance of succeeding if they cultivate the required abilities (Wiederkehr et al., 2015). The belief in meritocracy is a system-justifying tool that encourages people to make a sustained effort over time to achieve their goal (Laurin, Fitzsimons, \& Kay, 2011). For lower status group members, the belief in meritocracy promises mobility to the upper level life -- it 
provides hope. In this same way, hope protects the mental health of impoverished college students in China (Pan \& Zhou, 2009).

Major and her colleagues (2007) measured meritocracy belief with two beliefs: that success is linked to hard work (the Protestant Work Ethic [PWE]; Katz, \& Hass, 1988), and any individual can get ahead regardless of group membership (the Belief in Individual Mobility [IMB]; Major et al., 2002). PWE and IMB are shown to be moderately correlated ( $\mathrm{r}=.41$; Major et al., 2007). Both PWE and IMB assessments were developed by Levin and her colleagues in 1998.

It has been argued that lower status groups may endorse the belief in meritocracy in a different way than higher status groups. For example, when asked if the country is a merit-based justice system, lower status people were less likely to question or challenge the given state of affairs and have confidence that the system is based on fairness and is just with advancement due to merit likely (Jost et al., 2003). However, Chinese researcher Yang and his colleges (2016) concluded that a person's social class was positively correlated with system justification. Interestingly, Reynolds and Xian (2014) found that young, upper class Whites are most likely to see US. as a place where meritocratic elements rule. Older, lower class minorities, in contrast, are most likely to believe that non-meritocratic elements dominate.

According to Zhang (2015), China is perhaps the first country that adopted the principle of meritocracy in civil service management. The practice of meritocracy can be traced back to the Han Dynasty about 2000 years ago (Creel, 1964). China was also the first country to introduce meritocratic management to the public sector. As early as 1980 , Deng Xiaoping instructed that the cadre corps must achieve four transformations (sihua), 
that is, the cadres should become more revolutionary, younger, better educated, and professionally more competent. The latter three transformations all emphasized meritocracy as the target of cadre system reforms. However, as paths to upper level became narrower and fewer, people that suffered most from the current status perceived almost no control of their life and thus viewed the system as non-meritocratic and based less on justice (Yang et al., 2016).

Overall, the belief in meritocracy serves as a useful worldview of whether the system is fair and just. It encourages lower status groups to work hard to seek a better future. However, when a person's worldview is challenged by prejudice, there may be risk of physical and mental challenges. These issues will be discussed in the next section.

\section{The belief in meritocracy and discrimination}

Status ideologies are related to the way people view their world. Status ideologies, shared beliefs which provide an understanding for the differences between groups in society, help people to see their world as orderly and meaningful, with reasonable explanations of the world (Major et al., 2007). Status ideologies are developed through a person's experiences and understandings, but individual cultures will generally endorse specific ideologies. In industrialized countries such as the U.S. and China, a dominant status ideology is meritocracy — the belief that anyone, regardless of group membership, can be successful if he or she works hard enough or is talented enough (Plaut, Markus, \& Lachman, 2002). The stronger a population endorses the belief in meritocracy, the greater the system is seen as justified (Townsend et al., 2010). In the society groups which have greater advantage, a belief in meritocracy will tend to legitimize the existing status hierarchy as fair, just and well deserved (Jost \& Hunyady, 2002; Major, 1994) 
providing benefits such as increased mental and physical well-being (Major et al., 2007; O'Brien \& Major, 2005). However, groups who do not receive the benefits of a society will be disadvantaged.

There is research to support the idea that a belief in meritocracy is detrimental to disadvantaged groups of a society because it supports the idea that the lack of success of these group members is because they did not work hard enough or make the right decisions. Further, a non-belief in meritocracy sometimes acts as a protective factor of self-esteem for low-status groups members who perceive discrimination. For example, Major, Kaiser, O'Brien, \& McCoy (2007) found that when perceiving discrimination, Latino Americans who held meritocracy beliefs had decreased self-esteem and tended to blame their own group members, whereas increased self-esteem was observed for members of the group who rejected the idea of meritocracy. Similar results were found for Latina females versus white females, as well as for white females competing against white males. In these groups, perceived discrimination was positively related to chronic stress, as indicated by resting blood pressure, among women who endorsed meritocracy, but was negatively, although not significantly, related to resting blood pressure for women who rejected meritocracy (Townsend et al., 2010). Similar observations were made by Foster, Sloto and Ruby (2006), whereas when personal discrimination was indicated, stronger beliefs that meritocracy exists predicted decreased self-esteem and collective action as well as increased intergroup anxiety. Overall, this research would support the view that holding a belief in meritocracy promotes an internalization of inequality, which in turn may lead to low self-esteem and depression. 
Perceived discrimination has been found to be an important moderating factor for the impact of belief in meritocracy for low-status group members. Foster and colleagues (2006) identified a significant interaction between meritocracy beliefs and perceived discrimination. When perceived discrimination is high, a belief in meritocracy was related to negative outcomes such as a decrease in self-esteem. However, among those who reported less perceived discrimination, believing that meritocracy is present was shown to predict increased levels of self-esteem. In addition, women who strongly endorsed meritocracy demonstrated lower levels of self-esteem after reading that sexism is pervasive as compared to reading that it is rare. In contrast, women who strongly rejected meritocracy had higher levels of self-esteem after reading that sexism is pervasive compared to reading that it is rare (Major et al., 2007).

Additional factors have been suggested by research to moderate the impact of meritocracy towards members of low status groups. For example, O'Brien and Major (2005) concluded that meritocracy belief was negatively related to psychological wellbeing among members of low-status groups who highly identified with their group. However, a belief in meritocracy was positively related to well-being among members of low-status groups who did not highly identify with their ethnic group.

An important point to understand is that an individual who holds a belief in meritocracy and experiences societal disadvantages may internalize this disadvantage as being deserved, rather than an outcome of discrimination. In the same manner, lower status groups members who hold a belief in meritocracy tend to be less likely to attribute rejection from higher status as discrimination and they expect to be treated fairly 
(Townsend et al., 2010). Conversely, lower status group members who do not hold a belief in meritocracy may perceive a higher level of discrimination in a similar situation.

Besides these disadvantages, researchers also found that belief in meritocracy benefited the members of low-status groups in some ways. Endorsing meritocracy beliefs supports the view that personal life and future events are controllable. Perceived control is positively associated with psychological well-being (Pascoe \& SmartRichman, 2009). People with meritocracy beliefs perceived life outcomes as fair and deserved. In addition, perceptions of societal fairness encourage members of low status groups to work harder, persist longer, and invest in long term goals (Laurin, Fitzsimons, \& Kay, 2011). Furthermore, people with a strong belief in meritocracy were motivated to combat discrimination because it is counter to their idea of merit (Son Hing et al., 2002). A belief in meritocracy may also offer a distinct self-regulatory benefit for members of socially disadvantaged groups, encouraging them to maintain their pursuit of long-term goals (Laurin, Fitzsimons, \& Kay, 2011). Belief in meritocracy was found to benefit American women, low-SES women and women of color when facing discrimination by protecting their self-esteem and physical health via the mediation of perceived control (McCoy et al., 2013).

As I discussed at the beginning, status ideologies are heavily shaped by previous experience, and by particular groups under the frame of culture. China has a unique Eastern culture that differs in many ways from Western culture. Therefore, I would expect due to a greater acceptance of attitudes of hard work and persistence of long-term goals, belief in meritocracy may be beneficial within the Chinese culture even when facing discrimination. 


\section{Meritocracy in School}

Meritocracy in a school setting serves as an attribution tool to explain school success (Wiederkehr et al., 2015). Although there is evidence that several factors other than merit may explain school success including group belonging (Wiederkehr et al., 2015), family wealth and background (Reynolds \& Xian, 2014), a majority of western students accept the idea of school meritocracy (Wiederkehr et al., 2015).

Because merit is the only path for low status students to reach upward mobility, most research of meritocracy beliefs in school have focused on lower status students. As in other research which focuses on meritocracy, the benefit of meritocracy to students is controversial. Laurin and colleagues (2011) found that only low SES undergraduates showed greater intentions to persist in the face of poor exam performance to the extent that they believed in meritocracy, as opposed to high SES undergraduates who were unaffected. In addition, students were more willing to invest effort in career pursuits if they believed in societal justice. Ethnic minority participants, but not ethnic majority participants who read that societal justice was improving reported more willingness to invest resources in pursuit of long-term goals, relative to the control participants. However Darnon, Smeding and Redersdorff (2017) found that students with high levels of meritocracy belief had lower engagement in social events related to equalizing practices aimed at specially benefiting lower status students to help their own groups. Smith and Skrbis (2017) found that emphasizing meritocracy may compound the disadvantages of young people from less educated or vocational backgrounds, and those living in rural and regional Australia. Darnon and colleagues (2018) had similar findings, in that among high school student participants, a belief in meritocracy actually increased 
the achievement gap between students from low and high SES groups. In addition, among students with a low level of belief in meritocracy, students from lower SES groups had relatively high achievement. Conversely, among students with high meritocracy beliefs, the students from lower SES groups had lower levels of achievement.

In summary, comparing benefits of mental and physical well-being due to meritocracy beliefs, high-status group members seem to receive more benefits while the beliefs and benefits for low-status group members are more complex. Especially when facing discrimination which threatens their worldview of merit, belief in meritocracy may be beneficial or harmful to disadvantaged group members, impacted by such variables as the level of discrimination or cultural attributes. Within school environments where merit is emphasized as key to academic success, there is also debate as to whether disadvantaged students benefit from meritocracy beliefs. As worldview and status ideology is heavily influenced by culture, I expect to find unique patterns among Chinese college students as to their reaction towards discrimination depending on their differing beliefs of meritocracy.

\section{School Belongingness}

School belongingness has been described as engaging with peers and having good relationships with teachers, being a part of the school community, and an important component of academic success (Karcher \& Lee, 2002; Karcher \& Sass, 2010). Besides the physical and psychological issues as mentioned above, Loeb and Hurd (2017) contend that college students who perceive themselves as different, or inferior to their peers, because of differences such as social status, possessions, or perceived 
discrimination, may disconnect from their school environment and suffer a loss of selfefficacy. This can lead to physical, psychological and academic problems, even leaving without completing their degree.

Belonging is a fundamental human need (Allen \& Kern, 2017). For college students who have transitioned into a new environment and are seeking a sense of belonging or connection to others, having a sense of belonging to their school may fulfill strong social and emotional needs. This sense of belonging may impact an individuals' sense of purpose, life satisfaction, and well-being with positive outcomes such as physical health and psychological well-being (Allen \& Kern, 2017).

The term school belonging has similar meaning as other terms such as: school connectedness, school attachment and school bonding. It is defined as "the extent to which students feel personally accepted, respected, included, and supported by others in the school social environment" (Goodenow, 1993, p. 60). Studies have illustrated the benefit of school belonging, including psychological well-being, good academic outcomes and fewer negative behaviors (Allen et al., 2016; Allen \& Kern, 2017). Students' belonging to universities significantly predicted their academic performance and academic competence. In addition, students strongly connected to their school reported high levels of psychological adjustment, i.e. self-worth, and low levels of problematic behaviors (Pittman \& Richmond, 2009). College freshmen who feel a high level of school belonging showed higher academic efficiency, motivation and task value (Freeman et al., 2007).

According to Allen and Kern (2017), there are specific factors which influence school belongingness. One area of influence includes demographic characteristics of the student 
and school such as gender, age and race/ethnicity and school type/location. Another would be individual characteristics of students such as their motivation, specific personality traits, and emotional and mental health. Finally, individual and environmental factors are important such as the amount of support received from peers, teachers and parents as well as the students' perceptions of fairness and safety.

It is important to note that a students' perception of fairness may interact with their meritocracy belief to impact how the adolescent feels about their school. Note that a perception of fairness, when connected with a belief in meritocracy may impact how adolescents feel about their school. In addition, the social influence of peers and teachers, is also important. For college students who perceive discrimination, the effects of teachers and peers may be positive or negative.

Summed up, school belongingness plays an important role for college students through the influence on their mental and physical well-being, academic motivation and outcomes (Allen et al., 2016; Allen \& Kern, 2017). Previous research indicates that a belief in meritocracy and perceived discrimination affect school belonging, although school connectedness did not buffer the relationship between perceived discrimination and depressive symptoms or educational attainment (Pang, 2015). Including school belongingness in the research framework will help to better understand the impact of discrimination and a belief in meritocracy. 


\section{Chapter 3}

\section{METHODS}

In this chapter, I will discuss the participants, procedure and measures that were used in the study. I will also list the methods that were utilized for the data analysis.

\section{Participants and procedure}

There were 450 students from Beijing Normal University, China University of GeoScience, and Guangxi Normal University recruited for the study. Teaching professors were asked to distribute the Quick Response Code (QR code) to their students to scan into the online survey. All surveys were completed via the students' smartphones. Across all of the universities, there was one teacher who taught computer science, and all of the other teachers taught psychology courses. A lottery of four $50 \mathrm{RMB}$ gift cards (about \$8) was offered to encourage participation. Of the 450 responses, 15 were deleted because of repeated invariant answers, resulting in 435 valid responses.

The 435 student participants included 348 (80\%) undergraduate students and 87 (20\%) postgraduate students. There were 155 (35.6\%) male students and $280(64.4 \%)$ female students with 178 (40.9\%) self-identifying as urban dwellers, and $257(59.1 \%)$ as rural residents. There were 34 (7.8\%) from large cities, 99 (22.8\%) from middle size cities/towns, and 302(69.4\%) from small towns. Because there is an uneven economic development in China, I also asked the students to identify their social economic status (SES) with two criteria: local and national. Two items were used to collect this information; first, the students were asked to identify their financial status as compared to their local area. In a second question they were asked to again make this comparison in the context of the entire nation of China. The question for each of these was: compared to 
(local/whole nation) my family's financial status belongs to rich/above average/average/below average/poor. Please see Table 1 below for the distribution of SES status. In the analysis when comparing different SES levels, I used national SES to do the comparison. Students who reported "poor" and "below average" were recognized as low SES, and students who reported "average", "above average" and "rich" were recognized as high SES.

Table 1. Social Economic Status Locally and Nationally

\begin{tabular}{llccccc}
\hline SES & & Poor & \multicolumn{1}{l}{$\begin{array}{l}\text { Below } \\
\text { Average }\end{array}$} & Average & Above & Rich \\
& & \multicolumn{3}{c}{ Average } & \\
\hline Locally & $\mathrm{N}$ & 57 & 122 & 209 & 44 & 3 \\
& $\%$ & 13.1 & 28.0 & 48.0 & 10.1 & .7 \\
& Mean & 2.26 & 4.90 & 9.86 & 30.06 & 80 \\
\multirow{2}{*}{ Nationally } & $\mathrm{N}$ & 100 & 182 & 119 & 32 & 2 \\
& $\%$ & 23.0 & 41.8 & 27.4 & 7.4 & .5 \\
& Mean & 3.25 & 6.56 & 15.81 & 23.84 & 92.5 \\
\hline
\end{tabular}

Notes. Annual family income unit is 10 thousand RMB

\section{Measures}

Students responded to all survey items on a 7-point Likert-type scale ranging from 1 (strongly disagree) to 7 (strongly agree), with higher scores indicating the higher end of the scale. Some of the instruments have been introduced in China in the past, whereas some of the instruments are only developed in English. For the instruments without a Chinese version, a back-translation procedure (see Hambleton, 1996; Van de Vijver \& Hambleton, 1996) was done. To complete this, a full professor whose area of expertise is 
in psychology and who is fluent in Chinese and English, translated the Chinese version instruments into English and compared it with the original instrument items -- to assure the accuracy of the translation. Students were asked to complete the scales described in the following section.

\section{Meritocracy Belief}

The students' belief as to meritocracy were assessed by two measures developed through previous research. The first four items measure the belief that success is linked to hard work (the Protestant Work Ethic [PWE]; Katz, \& Hass, 1988; $\alpha=.60$ ), and the second four items measured the belief that any individual can get ahead regardless of group membership (the Belief in Individual Mobility [IMB]; Major et al., 2002; $\alpha=$ .85). PWE and IMB are shown to be moderately correlated ( $\mathrm{r}=.41$; Major et al., 2007). To adapt to Chinese society, all instances of "American" were changed to "China." The measurement items are listed as below:

1. Any people who don't get ahead should not blame the system; they really only have themselves to blame.

2. If people work hard they almost always get what they want.

3. Even if people want to work hard, they don't always get ahead. (reversed)

4. In China, getting ahead doesn't always depend on hard work. (reversed)

5. I feel that China is an open society where all individuals can achieve a high status.

6. Advancement in China society is possible for all individuals.

7. Individual members in certain groups are often unable to advance in Chinese society (reversed). 
8. Individual members of certain groups have difficulty achieving higher status (reversed).

\section{Perceived discrimination}

Perceptions of discrimination towards ones' specific group was measured with two items $(\alpha=.87$; Major et al., 2007). "My region group is discriminated against." and "Students like me experience discrimination." I also developed 4 items to measure the sensitivity of college students to perceived discrimination in their daily life, e.g., "I have noticed some prejudicial behavior towards rural/poor students." These scale items are listed below:

1. My region group is discriminated against.

2. Students like me experience discrimination

3. I have noticed some prejudicial behavior towards rural/poor/female students

4. People who feel that they are discriminated against are just oversensitive

5. Professors seem to discriminate against students depending on the region they are from.

6. My roommates talk as though they are prejudiced towards rural/poor/female people

\section{Belonging to school}

Students' sense of belonging to school was measured by the Psychological Sense of School Membership (PSSM) scale (Goodenow, 1993) $(\alpha=.77 \sim$ .88). The instrument has been translated into Chinese $(\alpha=.71 \sim .88$; Cheung \& Hui, 2003). In addition, the first 3 items are from the Hemingway Connected to 
School Measurement about connecting to school/friends. These items were also translated into Chinese $(\alpha=.72)$.

Eight items measure an individual's sense of belonging to his/her school.

1. I put as little effort into my college work as I can (reversed).

2. Many of the other students bother me (reversed).

3. I like working on projects with the students in my classes.

4. I feel proud of belonging to my college.

5. I am treated with as much respect as other students.

6. I feel very different from most other students here (reversed).

7. The teachers here respect me.

8. There's at least one teacher or other adult in this school I can talk to if I have a problem.

\section{Perceived control}

Participants answered 7 questions assessing their perceived control over life outcomes (Pearlin \& Schooler, 1978; $\alpha=.78$; Chinese version $\alpha=.70$ ).

The items are listed below:

1. I have little control over the things that happen to me (reversed);

2. There is really no way I can solve some of the problems I have(reversed);

3. There is little I can do to change many of the important things in my life (reversed);

4. I often feel helpless in dealing with the problems of life (reversed)

5. Sometimes I feel that I'm being pushed around in life (reversed)

6. What happens to me in the future mostly depends on me 
7. I can do just about anything I really set my mind to do

\section{Self-esteem}

Self-esteem was assessed with the 10- item Rosenberg Global Self-Esteem Scale $(\alpha=$ .89; Rosenberg, 2015). The scale was introduced to China in 1993 by the psychology department of Beijing Normal University $(\alpha=.83)$. In addition, the 7-item Social SelfEsteem subscale of Heatherton and Polivy $(\alpha=.88 ; 1991)$ was used. The instrument was introduced in Mainland China by Zhang and colleagues $(\alpha=.84 ; 2005)$. State Self-Esteem Scale was selected to collect more information about self-esteem. Because both of the self-esteem scales are highly correlated $(r \mathrm{~s}=.54 \sim .64, p<.001)$ and combined a highly reliable score ( $\alpha=.93$; see Major et al., 2007), they were aggregated into a composite measure of personal self- esteem. A factor analysis was conducted before combining the items.

Items are listed as:

1. Overall, I am satisfied about myself

2. At times I think I am not good at all (reversed)

3. I feel that I have a number of good qualities

4. I am able to do things as well as most other people

5. I feel I do not have much to be proud of (reversed)

6. I certainly feel useless at times (reversed)

7. I feel that I am a person of worth, at least on an equal plane with others

8. I wish I could respect myself more (reversed)

9. In general, I feel that I am a failure (reversed)

10. I have a positive attitude about myself 
11. I worry about whether others regard me as a success or failure (reversed)

12. I feel self-conscious (reversed)

13. I feel displeased with myself (reversed)

14. I am worried about what other people think of me (reversed)

15. I feel inferior to others at this moment (reversed)

16. I am concerned about the impression I am making (reversed)

17. I am worried about looking foolish (reversed)

\section{Victim blame}

Participants completed a 3-item measure of group blame. I created these items based on Grubb and Turner's work (2012).

Scale items:

1. It is some peasants fault that they received negative views.

2. People from rural areas are prejudged because media exaggerated the negative aspect.

3. People from urban prejudge rural residence to make them look better.

\section{Effort}

A meta-research indicated a lack of a generally accepted measure of effort (Naylor et al., 2013). Instead, the researchers suggested measuring effort in two dimensions: time commitment and work intensity. Hence, I designed four items to be used to examine students' effort during college study. Items 1 and 4 measured the time commitment by absolute time and comparison with the classmates, and items 2 and 3 measured work intensity by comparing if the student believes he/she does his/her best.

Scale item 
1. On average, I study _ _ hours per day (besides classes).

2. I hope I could study ___ hours per day (besides classes).

3. I study harder compared to when I was in high school.

4. I don't study as hard as my classmates (reversed).

\section{Academic performance}

Academic performance is mainly self-reported. Less than $17 \%$ of the students agreed to release their midterm scores. Further, as they are from different departments of different universities, these scores are not useful. According to previous research (Cole \& Gonyea, 2010; Kuncel \& Thomas, 2005), students tend to over-report their academic performance scores during self-report. Chinese researchers (Guo et al., 2018) pointed out that college students had over-reported by $15-21 \%$ their College Entrance Exam (CEE) scores. Therefore, the self-report academic performances lack validity and will not be used in the analysis. Rather, I am interested to know if they expect improvement to their scores; therefore, I asked specific questions regarding scale items

1. For the last final exam, I rank about percentile in my department.

2. For this semester, I think I will rank about percentile in my department.

\section{Demographic Information}

The following items were used to collect participants' biological information

1. I am a(an) undergraduate/graduate student.

2. I am a male/female.

3. I was enrolled in UNDERGRADUATE by year

4. My major is

5. My major belongs to Engineering/Literature/Art \& Science. 
6. I am from province.

7. I am from urban/rural area.

8. My hometown is a small/medium/large town/city.

9. Compared to LOCAL residence, my family financial status belongs to rich/above average/medium/below average/poor.

10. Nationally, my family financial status belongs to rich/above average, medium/below average/poor.

11. The annual income of my family is

12. I live (lived) with my (father/mother/grandparents/siblings/others).

13. My father's highest education level is

14. My mother's highest education level is

15. The highest education level of the people who live (lived) with me is

16. How true is this statement? Friends and relatives about my age all go (went) to college.

\section{Miscellaneous}

1. This college/university is the one that I originally wanted to enroll in.

2. This major is the one that I originally wanted to study.

3. My parents/relatives are proud that I enrolled in college.

4. I have a boyfriend/girlfriend ___ (yes/no).

5. Getting into a relationship is one of my goals in college.

\section{Factor Analysis}

In this study, students' belief in meritocracy, perceived control, school belongingness, self-esteem and perceived discrimination were measured. Some of the scales, such as 
belief in meritocracy, belonging to school and self-esteem were combined by two similar assessments. The meritocracy belief scale, on the other hand, didn't have a Chinese version. Therefore, factor analysis is necessary to assure validity and reliability of the scales. An exploratory factor analysis (EFA) was used to understand the structure of translated belief in meritocracy scale (Costello \& Osborne, 2005). Then a confirmatory factor analysis (CFA) was conducted for all of the scales to refine the number of measured items. As for EFA for meritocracy belief scale, a principal axis factoring (PAF) method was used to extract factors, and a Varimax rotation method was conducted. Two factors were extracted, as shown in Table 2.

Table 2 . Exploratory Factor Analysis for Belief in Meritocracy Scale

\begin{tabular}{ll} 
Factor & \\
\hline 1 & 2
\end{tabular}

1. Any people who don't get ahead should not blame the system; they really only have themselves to blame.

2. If people work hard they almost always get what they want.

3. Even if people want to work hard, they don't always get ahead.

4. In China, getting ahead doesn't always depend on hard work.

5. I feel that China is an open society where all individuals can achieve a high status. 
6. Advancement in China society is possible for all

individuals.

7. Individual members in certain groups are often unable to advance in Chinese society.

8. Individual members of certain groups have difficulty achieving higher status.

With a closer look at these items, the major difference between the two factors tended to be determined by the way the questions were asked. Factor 1 included all the normal items while factor 2 included all the reversed items. Therefore, splitting the items into two factors didn't make sense. Therefore, I chose to treat the scale as one factor.

As for the CFA, items with insignificant or weak $(<.50)$ indicator-factor loading were removed, as illustrated in Figure 4 below. IBM SPSS AMOS was used to conduct the analysis. At the end of the CFA analysis, all the latent variables were exported for future analysis. 


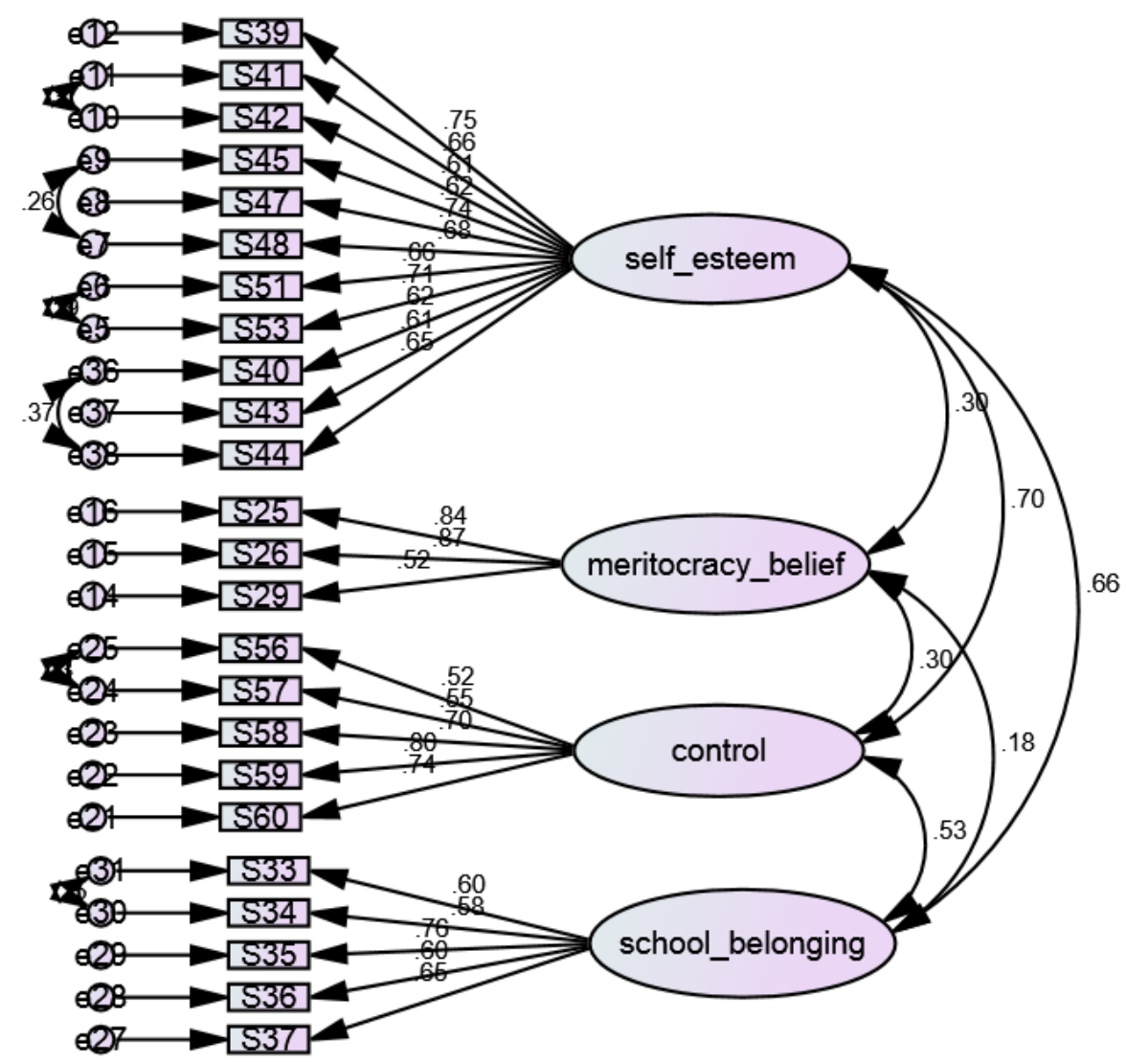

Figure 3. Confirmatory factor analysis for self-esteem, meritocracy belief, perceived control and school belongings.

The CFA model has an acceptable model fit $\left(\chi^{2}=644.358, d f=240\right.$, CFI $=.910$, TLI $=.896, \mathrm{RMSEA}=.062, \mathrm{SRMR}=.059)$. There is no significant difference at model level between high and low SES levels $\left(\chi^{2}=12.776, d f=20, p=.887\right)$, nor did it exist between males and females $\left(\chi^{2}=12.131, d f=20, p=.911\right)$, or urban and rural students $\left(\chi^{2}=\right.$ 16.776, $d f=20, p=.667)$.

\section{Self-esteem}

Eleven items remained with Cronbach's alpha $=.90$, Composite Reliability $(\mathrm{CR})=$ .897 , and Maximum Reliability $(\operatorname{MaxR}(\mathrm{H}))=.90$

The remaining items are listed below: 
1. Overall, I am satisfied about myself; $(\boldsymbol{\lambda}=.746)$

2. At times I think I am not good at all; $(\boldsymbol{\lambda}=.624)$

3. I feel that I have a number of good qualities; $(\lambda=.665)$

4. I am able to do things as well as most other people; $(\boldsymbol{\lambda}=.606)$

5. I feel I do not have much to be proud of; $(\boldsymbol{\lambda}=.607)$

6. I certainly feel useless at times; $(\boldsymbol{\lambda}=.647)$

7. I feel that I am a person of worth, at least on an equal plane with others; $(\boldsymbol{\lambda}=$ $.621)$

8. In general, I feel that I am a failure; $(\boldsymbol{\lambda}=.741)$

9. I have a positive attitude about myself; $(\boldsymbol{\lambda}=.680)$

10. I feel displeased with myself; $(\boldsymbol{\lambda}=.663)$

11. I feel inferior to others at this moment. $(\boldsymbol{\lambda}=.775)$

\section{Belief in meritocracy}

Only 3 items remained for the measurement of meritocracy belief. They have a Cronbach's alpha of $.784, \mathrm{CR}=.798, \operatorname{MaxR}(\mathrm{H})=.855$.

The items are listed below.

1. Even if people want to work hard, they don't always get ahead; $(\boldsymbol{\lambda}=.840)$.

2. In China, getting ahead doesn't always depend on hard work; $(\boldsymbol{\lambda}=.870)$.

3. Individual members in certain groups are often unable to advance in Chinese society: $(\lambda=.524)$.

\section{School Belonging}

There were 5 items remaining for the measurement of school belonging with a Cronbach's alpha $=.781, \mathrm{CR}=.776, \operatorname{MaxR}(\mathrm{H})=.789$. 
The items are listed below.

1. I like working on projects with the students in my classes; $(\lambda=.597)$.

2. I feel proud of belonging to my college; $(\lambda=.583)$.

3. I am treated with as much respect as other students; $(\boldsymbol{\lambda}=.761)$.

4. I feel very different from most other students here; $(\lambda=.602)$.

5. The teachers here respect me. $(\boldsymbol{\lambda}=.648)$.

\section{Perceived Control}

There were 5 items remaining for the measurement of perceived control, with Cronbach's alpha $=.807, \mathrm{CR}=.800, \operatorname{MaxR}(\mathrm{H})=.827$.

The items are listed below:

1. I have little control over the things that happen to me; $(\boldsymbol{\lambda}=.518)$.

2. There is really no way I can solve some of the problems I have; $(\boldsymbol{\lambda}=.554)$.

3. There is little I can do to change many of the important things in my life; $(\boldsymbol{\lambda}=.7)$.

4. I often feel helpless in dealing with the problems of life; $(\boldsymbol{\lambda}=.802)$.

5. Sometimes I feel that I'm being pushed around in life. $(\boldsymbol{\lambda}=.741)$.

\section{Perceived Discrimination}

Only 2 items were used to detect perceived discrimination. They have a Cronbach's alpha $=.851$. I simply used their sum for analysis. The items are:

1. My region group is discriminated against.

2. Students like me experience discrimination.

\section{Victim Blame}

There are only 2 items left to measure victim blame. They have a Cronbach's alpha = .428. Their sum was used for analysis. The items are: 
1. People from rural areas are prejudged because media exaggerated the negative aspect.

2. People from urban prejudge rural residence to make them look better.

\section{Analysis}

Question 1: What level of discrimination do students who are enrolled in Chinese colleges perceive?

1. What demographic factors predict perceptions of discrimination in Chinese college students?

A linear regression was used to determine the demographic factors that predict perceived discrimination.

1. What proportion of students are aware of discrimination?

Descriptive analysis was used to understand the proportion of students who were aware of discrimination. Furthermore, a group comparison method, student t-test was conducted to learn if there is any difference between gender, location or SES groups.

1. Does perceived discrimination predict self-esteem, perceptions of control, belief in meritocracy, school belongings and victim blame?

An SEM path analysis was conducted to understand the relationship between perceived discrimination and self-esteem, perceptions of control, belief in meritocracy, school belonging and victim blame. In addition, multigroup analysis was used to learn if the relationships differ between gender, location and SES groups.

Question 2: What is the level of college students' belief in meritocracy?

1. What demographic factors can predict the belief in meritocracy? 
A linear regression analysis was used to determine the demographic factors that predict belief in meritocracy.

2. Does belief in meritocracy predict self-esteem, perceptions of control, and school belongingness while controlling for perceptions of discrimination?

An SEM path analysis was conducted to understand the relationship between meritocracy belief and self-esteem, perceptions of control, school belongings and victim blame while controlling for perception of discrimination. In addition, a multigroup analysis was used to learn if the relationships differ between gender, location and SES groups.

Question 3. Does belief in meritocracy predict students' sense of belongingness to school and self-esteem via perceived control while controlling for perceived discrimination?

An SEM path analysis was conducted to understand the relationship between meritocracy belief and self-esteem, school belonging and victim blame with the mediation of perception of control while controlling for perception of discrimination. In addition, multigroup analysis was used to learn if the relationships differ between gender, location and SES groups 


\section{Chapter 4}

\section{RESULTS}

\section{Research Question 1}

Research Question 1: What level of discrimination do students who are enrolled in Chinese colleges perceive?

Table 3 illustrates the frequency of the responses of perceived discrimination measurement with the 2 items, with percentage in parentheses.

1. My region group is discriminated against.

2. Students like me experience discrimination.

Table 3. Response of Perceived Discrimination. Percentage in Parenthesis

\begin{tabular}{rrrrrrrr}
\hline Item & \multicolumn{1}{l}{ Strongly } \\
\multicolumn{2}{c}{ Disagree } & & & & & Strongly \\
\hline 1 & $128(29.4)$ & $166(38.2)$ & $20(4.6)$ & $67(15.4)$ & $40(9.2)$ & $13(3.0)$ & $1(0.2)$ \\
2 & $128(29.4)$ & $181(41.6)$ & $24(5.5)$ & $63(14.5)$ & $29(6.7)$ & $10(2.3)$ & $0(0)$ \\
\hline
\end{tabular}

In this study, the perceived discrimination was calculated as sum of item 1 and 2. Table 4 illustrated means and standard deviation (SD) for each group.

Table 4. Means and SD of Perceived Discrimination

\begin{tabular}{llccc}
\hline & & $\mathrm{N}$ & Mean & $\mathrm{SD}$ \\
\hline gender & male & 155 & 4.697 & 2.482 \\
& female & 280 & 4.871 & 2.669 \\
area & urban & 178 & 4.41 & 2.474 \\
& rural & 257 & 5.086 & 2.658
\end{tabular}




\begin{tabular}{|c|c|c|c|c|}
\hline \multirow[t]{2}{*}{ level } & undergraduate & 348 & 4.739 & 2.610 \\
\hline & graduate & 87 & 5.092 & 2.568 \\
\hline \multirow[t]{3}{*}{ town size } & large & 34 & 4.412 & 2.583 \\
\hline & median & 99 & 4.253 & 2.336 \\
\hline & small & 302 & 5.036 & 2.662 \\
\hline \multirow[t]{5}{*}{ locally SES } & rich & 3 & 6.333 & 3.215 \\
\hline & above average & 44 & 4.432 & 2.405 \\
\hline & average & 209 & 4.632 & 2.495 \\
\hline & under average & 122 & 4.910 & 2.733 \\
\hline & poor & 57 & 5.456 & 2.759 \\
\hline \multirow[t]{5}{*}{ nationally SES } & rich & 2 & 7.500 & 3.536 \\
\hline & above average & 32 & 4.156 & 2.157 \\
\hline & average & 119 & 4.294 & 2.355 \\
\hline & under average & 182 & 4.857 & 2.567 \\
\hline & poor & 100 & 5.490 & 2.894 \\
\hline
\end{tabular}

There were no reported differences among male and female students in their perceived discrimination $(\mathrm{t}=.67, d f=433, \mathrm{p}=.503)$. Nor did it differ between undergraduate and graduate students $(\mathrm{t}=1.133, d f=433, \mathrm{p}=.258)$. However, students from rural areas reported a significantly higher perception of discrimination than their urban peers $(\mathrm{t}=2.716, d f=397.485, p=.007)$. Students from small towns perceived greater discrimination than their middle size town/city peers $(\mathrm{F}=3.863, d f=2,432, p=$ .022). Groups reporting local SES didn't differ as to the amount of perceived discrimination $(\mathrm{F}=1.668, d f=4,430, p=.156)$. However, significant difference was 
observed among national SES groups $(\mathrm{F}=4.04, d f=4,430, p=.003)$, and SES group identified as poor reported a higher level of perceived discrimination than the group reporting as average.

1. What demographic factors predict perceptions of discrimination in Chinese college students?

Perceived discrimination was predicted by national SES and if the student lived with single mother or grandparents before they entered college $(\mathrm{F}=6.461, d f=3,341, p=$ $.000)$. National SES explained $2.1 \%$ of the variances of perceived discrimination. In addition, if the student lived with a single mother or grandparents, the variables explained $.9 \%$ and $.6 \%$ of the variance. The regression equation can be illustrated as:

Discrimination $=2.945+.492 *$ nationalSES $+.924 *$ singleMom $-.884 *$ grandparents Students reporting a lower level of national SES perceived more discrimination. One category lower in national SES status predicts on average .169 category more perceived discrimination. In addition, students who lived with single mothers perceived more discrimination, and those who lived with grandparents perceived less discrimination.

1. What proportion of students are aware of discrimination?

Three items were used to detect if students were aware of discrimination. They are:

1. I have noticed some prejudicial behavior towards rural/poor/female students.

2. Professors seem to discriminate against students depending on the region they are from.

3. My roommates talk as though they are prejudiced towards rural/poor/female people.

Table 5 illustrates the frequency of the responses, with percentage in braces. 
Table 5. Response of Awareness of Discrimination. Percentage in Parenthesis

\begin{tabular}{|c|c|c|c|c|c|c|c|}
\hline \multirow[t]{2}{*}{ Item } & Strongly & & & & & & \multirow[t]{2}{*}{ Strongly } \\
\hline & Disagree & & & & & & \\
\hline 1 & $39(9.0)$ & $72(16.6)$ & $46(10.6)$ & $90(20.7)$ & $87(20.0)$ & $87(19.8)$ & $15(3.4)$ \\
\hline 2 & $38(8.7)$ & $102(23.4)$ & $49(11.3)$ & $94(21.6)$ & $97(22.3)$ & $45(10.3)$ & $10(2.3)$ \\
\hline 3 & $99(22.8)$ & $151(34.7)$ & $49(11.3)$ & $73(16.8)$ & $45(10.3)$ & $13(3.0)$ & $5(1.1)$ \\
\hline
\end{tabular}

Approximately a quarter of students (23.2\%) noticed prejudging behaviors towards lower status students. Students who reported prejudging behavior from professors totaled $12.6 \%$, and $4.1 \%$ of students reported prejudging behavior from their roommates. Means and SD of each group are listed in table 6.

Table 6. Means and SD of Awareness of Discrimination

\begin{tabular}{|c|c|c|c|c|c|c|c|c|}
\hline & & \multicolumn{3}{|c|}{$\underline{\text { Item1 }}$} & \multicolumn{2}{|c|}{ Item2 } & \multicolumn{2}{|c|}{ Item3 } \\
\hline & & $\mathrm{N}$ & Mean & SD & Mean & $\mathrm{SD}$ & Mean & SD \\
\hline \multirow[t]{2}{*}{ gender } & male & 155 & 3.768 & 1.716 & 3.310 & 1.565 & 2.684 & 1.476 \\
\hline & female & 280 & 4.118 & 1.678 & 3.846 & 1.593 & 2.721 & 1.496 \\
\hline \multirow[t]{2}{*}{ area } & urban & 178 & 3.854 & 1.714 & 3.640 & 1.635 & 2.837 & 1.541 \\
\hline & rural & 257 & 4.089 & 1.683 & 3.665 & 1.583 & 2.619 & 1.445 \\
\hline \multirow[t]{2}{*}{ level } & undergraduate & 348 & 3.856 & 1.700 & 3.523 & 1.584 & 2.716 & 1.515 \\
\hline & graduate & 87 & 4.540 & 1.583 & 4.184 & 1.574 & 2.678 & 1.377 \\
\hline town & large & 34 & 3.676 & 1.788 & 3.647 & 1.721 & 2.824 & 1.547 \\
\hline \multirow[t]{2}{*}{ size } & median & 99 & 3.677 & 1.754 & 3.303 & 1.508 & 2.596 & 1.406 \\
\hline & small & 302 & 4.132 & 1.655 & 3.772 & 1.607 & 2.732 & 1.509 \\
\hline locally & rich & 3 & 4.000 & 1.000 & 4.333 & 1.528 & 3.000 & 2.000 \\
\hline
\end{tabular}




\begin{tabular}{|c|c|c|c|c|c|c|c|c|}
\hline \multirow[t]{2}{*}{ SES } & above average & 44 & 3.909 & 1.865 & 3.136 & 1.812 & 2.886 & 1.807 \\
\hline & average & 209 & 4.105 & 1.649 & 3.775 & 1.579 & 2.761 & 1.503 \\
\hline & under average & 122 & 3.934 & 1.680 & 3.689 & 1.596 & 2.525 & 1.337 \\
\hline & poor & 57 & 3.772 & 1.823 & 3.509 & 1.490 & 2.754 & 1.455 \\
\hline national & rich & 2 & 3.500 & 0.707 & 5.000 & 1.414 & 3.000 & 2.828 \\
\hline \multirow[t]{4}{*}{ SES } & above average & 32 & 4.125 & 1.827 & 3.344 & 1.677 & 2.813 & 1.575 \\
\hline & average & 119 & 3.706 & 1.724 & 3.513 & 1.702 & 2.790 & 1.615 \\
\hline & under average & 182 & 4.137 & 1.593 & 3.742 & 1.564 & 2.670 & 1.40 \\
\hline & poor & 100 & 4.040 & 1.803 & 3.740 & 522 & 2.640 & 1. \\
\hline
\end{tabular}

Female students noticed more prejudging behaviors than their male counterparts $(\mathrm{t}=$ 2.068, $d f=433, p=.039$ ). They also noticed more prejudging behavior from professors $(\mathrm{t}=3.386, d f=433, p=.001)$. Students from rural and urban areas did not report a difference in their level of discrimination awareness. However, compared to undergraduate students, graduate students noticed more discriminatory behavior $(\mathrm{t}=$ $3.401, d f=433, p=.001)$ and prejudging behavior from professors $(\mathrm{t}=3.485, d f=433, p$ $=.001)$. Students from small towns tended to notice more prejudging behaviors from professors than their median size city/town peers $(\mathrm{F}=3.22, d f=2,432, p=.021)$. No difference was found among local SES or national SES groups.

1. Does perceived discrimination predict self-esteem, perceptions of control, belief in meritocracy, school belongings and victim blame?

A path analysis was conducted to understand the consequences of perceived discrimination, as shown in Figure 4. 


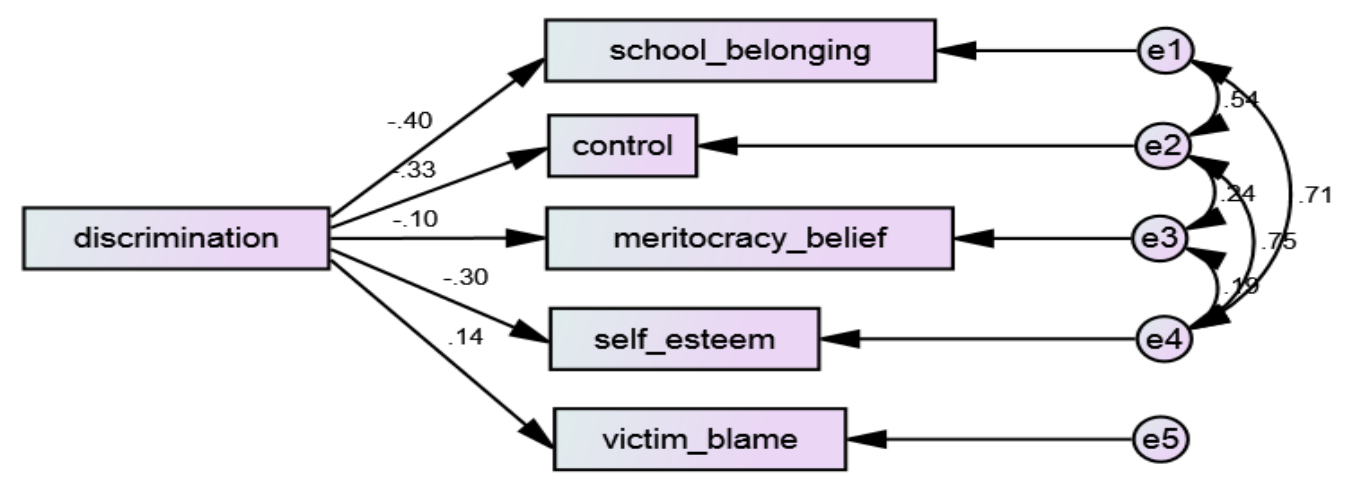

Figure 4. Path analysis of consequences of perceived discrimination

The path analysis has an acceptable model fit $\left(\chi^{2}=25.322, d f=5, p=.000\right.$. CFI $=$ $.978, \mathrm{TLI}=.934, \mathrm{RMSEA}=.097, \mathrm{SRMR}=.0585)$. Perceived discrimination decreases students' sense of belonging to school $(\beta=-.401, p=.000)$, lowers their perceived control $(\beta=-.326, p=.000)$ and self-esteem $(\beta=-.299, p=.000)$, decreases their belief on meritocracy ( $\beta=-.102, p=.033)$, and predicts a tendency to blame the victim more ( $\beta$ $=.136, p=.004)$.

Male and female students did not show differences as to the consequences of perceived discrimination $\left(\chi^{2}=9.939, d f=5, p=.077\right)$, nor did students from rural or urban areas $\left(\chi^{2}=3.512, d f=5, p=.622\right)$. To compare the difference among SES groups, I divided SES in two groups. Students who reported rich or above average were grouped as high SES group, whereas students reported poor or below average were grouped into low SES group. No significant differences were determined by path analysis between high and low SES groups both locally $\left(\chi^{2}=3.413, d f=5, p=.637\right)$ or nationally $\left(\chi^{2}=\right.$ 7.437, $d f=5, p=.190)$. 


\section{Research question 2}

Question 2: What is the level of college students' belief in meritocracy?

The imputed factor score of meritocracy belief has a distribution of mean 3.79 and standard deviation 1.303, as shown in figure 5. Most students did not hold very strong beliefs for or against meritocracy belief.

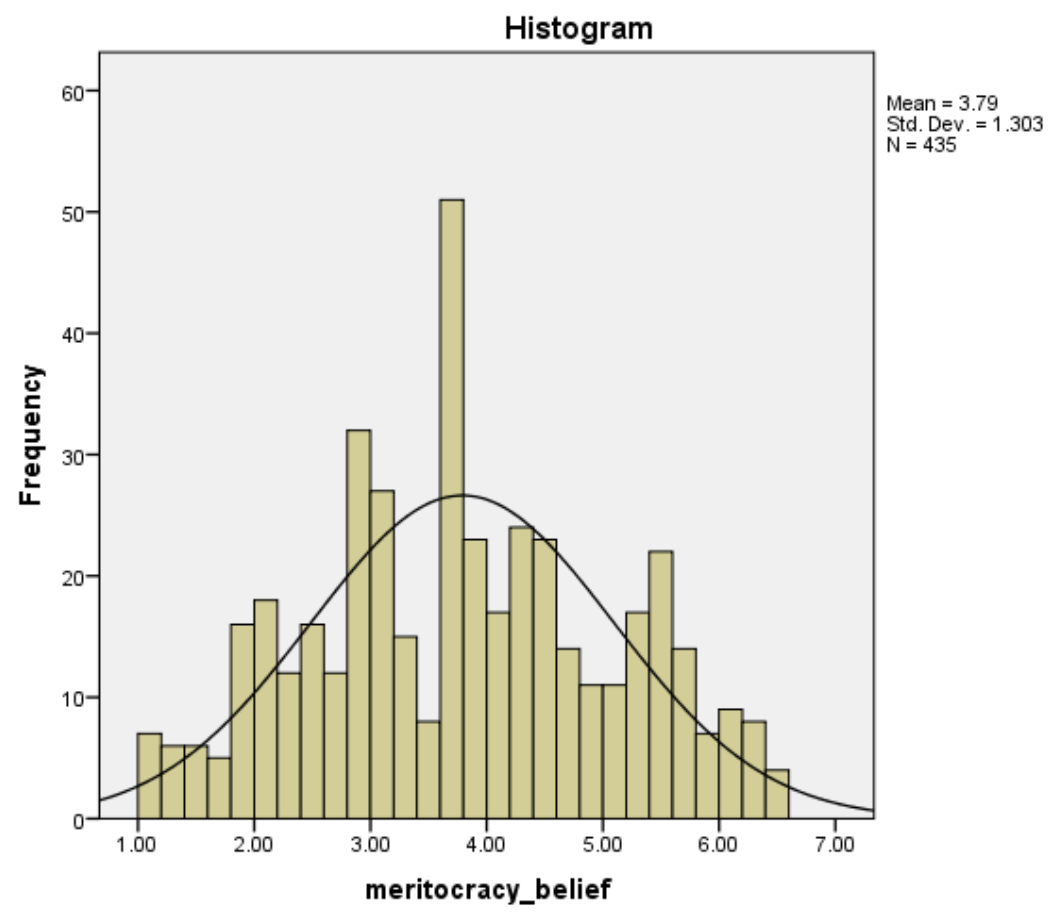

Figure 5. Distribution of imputed meritocracy belief

A path analysis was used to check group difference on meritocracy belief, as shown in figure 6.

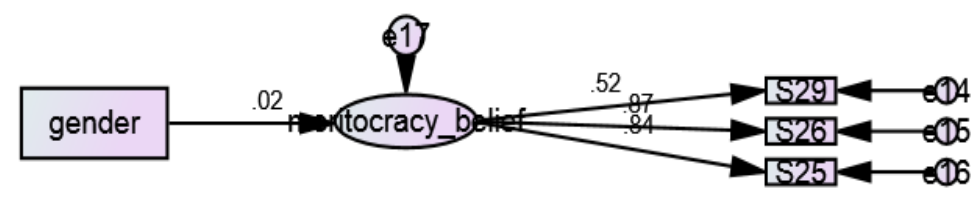

Figure 6. Group means analysis for belief in meritocracy 
All the models have insignificant $\chi^{2}$ which indicated a good model fit. Results showed no significant group mean difference between gender $(\beta=.022, p=.665)$, rural/urban groups $(\beta=.049, p=.341)$, high vs. low SES groups locally $(\beta=.106, p=$ .139). However, national SES high vs. low groups have a significant path loading on meritocracy belief $(\beta=.154, p=.011)$.

1. What demographic factors predict belief in meritocracy?

The family annual income is the only factor that was significant in the linear regression model $(\beta=.279, p=.045)$. However, it is a weak predictor that explained $5.9 \%$ of the variance. The standardized regression model can be illustrated as:

Meritocracy belief $=.279 *$ income.

1. Does belief in meritocracy predict self-esteem, perceptions of control, and school belongingness while controlling for perceptions of discrimination?

A path analysis was used to find out the influence of meritocracy belief, as shown in Figure 7. 


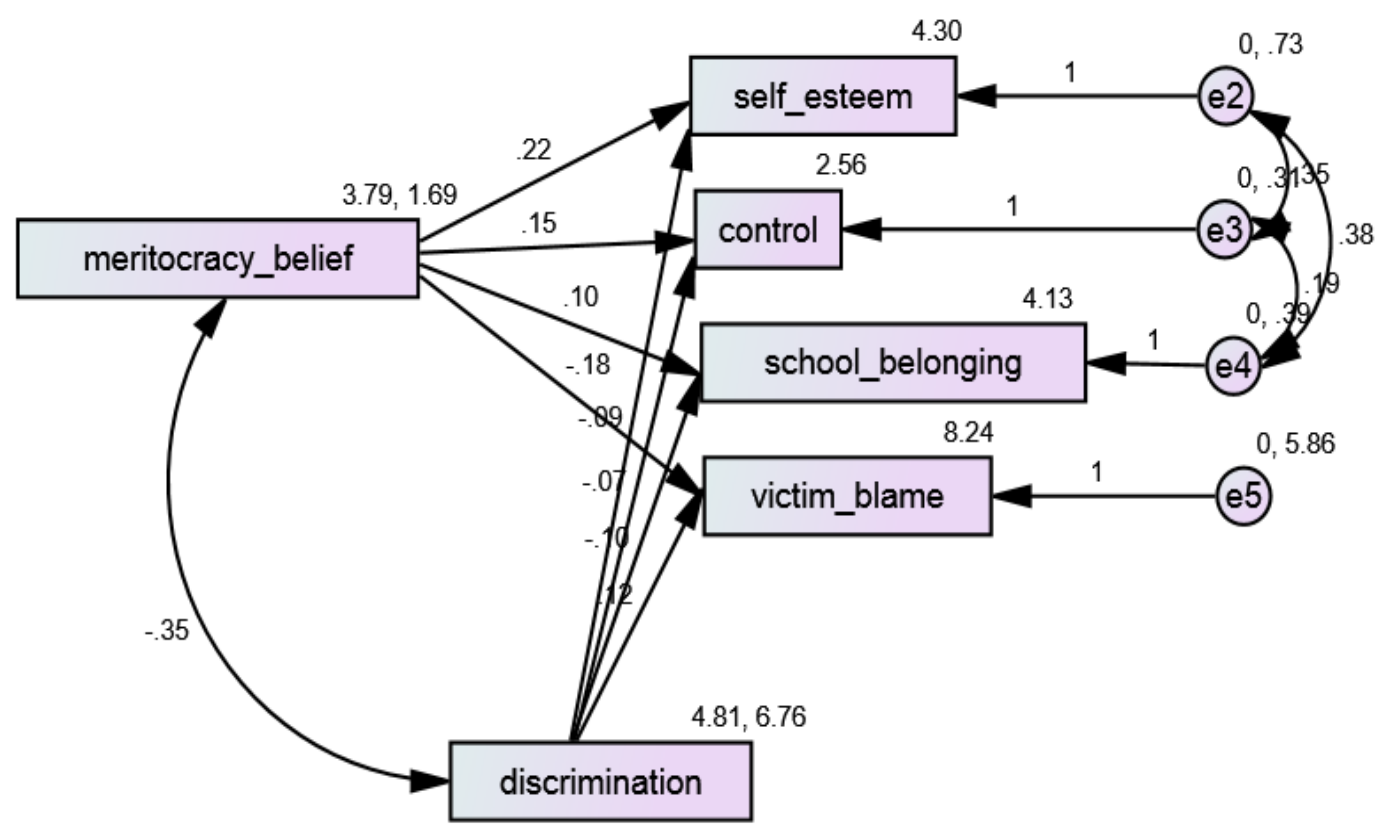

Figure 7. Path analysis of influence of meritocracy belief

The model has an acceptable model fit $\left(\chi^{2}=3.755, d f=3, p=.289\right.$. CFI $=.999$, TLI $=.996, \mathrm{RMSEA}=.024, \mathrm{SRMR}=.0229)$. With the control of perceptions of discrimination, the belief in meritocracy has a significant positive relationship with selfesteem $(\beta=.309, p=.000)$, perceptions of control $(\beta=.320, p=.000)$, belongingness to school $(\beta=.182, p=.000)$, and a negative relationship with victim blame $(\beta=-.098, p=$ $.039)$.

\section{Research Question 3}

Question 3. Does belief in meritocracy predict students' belongingness to school and self-esteem via perceived control while controlling for perceived discrimination?

A path analysis was conducted to learn the benefit of belief in meritocracy, as shown in Figure 8: 


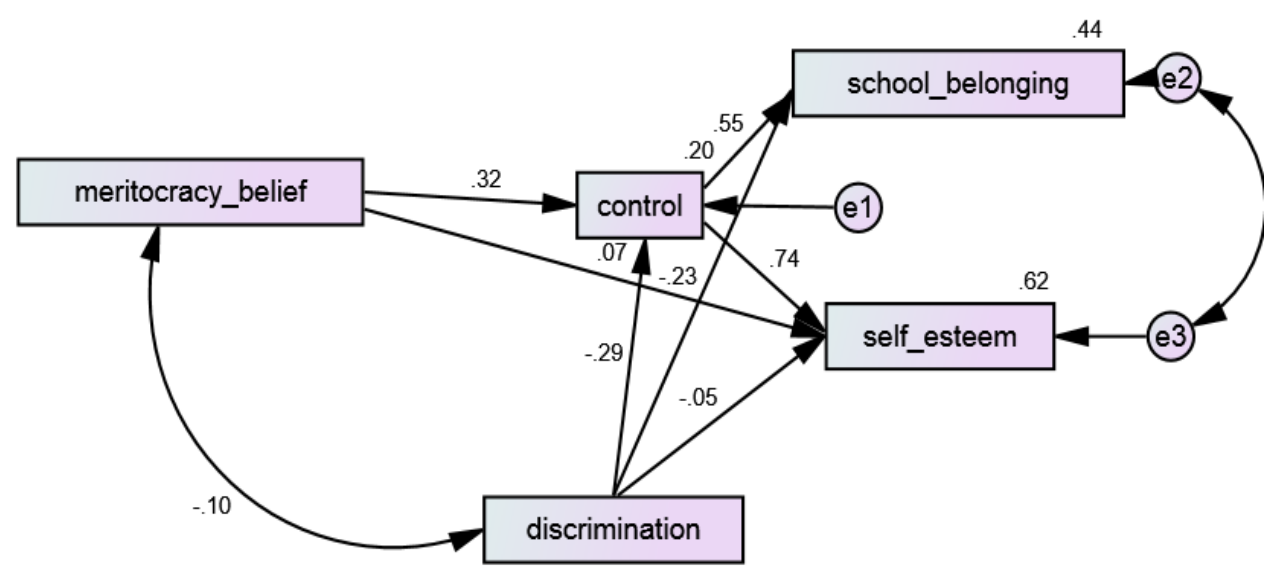

Figure 8. Path analysis of beneficial of meritocracy belief

The path analysis has an acceptable model fit $\left(\chi^{2}=2.474, d f=2, p=.290 . \mathrm{CFI}=\right.$ $.999, \mathrm{TLI}=1.011, \mathrm{RMSEA}=.032, \mathrm{SRMR}=.0015)$. In the model, perceived control weakens the relationship of meritocracy towards self-esteem from $.309(p=.000)$ to .072 $(p=.024)$, and mediated relationship of meritocracy to school belongingness from .182 ( $p$ $=.000)$ to $.006(p=.873)$.

A multigroup path analysis was conducted to test group differences on meritocracy's influence on other factors. The results showed no difference between male and female $\left(\chi^{2}\right.$ $=9.535, d f=8, p=.299)$, rural and urban $\left(\chi^{2}=3.597, d f=8, p=.892\right)$, high and low SES both locally $\left(\chi^{2}=6.449, d f=8, p=.597\right)$ or nationally $\left(\chi^{2}=7.806, d f=8, p=.453\right)$. 


\section{Chapter 5}

\section{DISCUSSION}

In this study, I compared Chinese college students' perception of discrimination according to a higher or lower belief in meritocracy. I also investigated how students' self-esteem and sense of school belonging is affected by discrimination. As a possible self-coping tool to defend discrimination, the belief in meritocracy was investigated for its benefits and predictors. In this chapter, I will draw conclusions regarding the findings, discuss the limitations of the study as well as directions for future research.

\section{Discrimination}

Students from rural areas, small towns and low SES at the national level reported perceiving more prejudicial behaviors. However, there was no difference as to gender on the perception of discrimination. National SES level predicted perceived discrimination as well as which family members the student lived with before they entered college. Specifically, students who lived with a single mother or relatives other than their parents and grandparents perceived more discrimination. Other factors, such as the parents' education level, annual income, or similar education level as their peers did not predict perceived discrimination.

Feeling discriminated against is harmful to students in multiple ways. Besides decreased self-esteem and perceived loss of control as was found in previous studies (e.g., Major \& O’Brien, 2005; Schmitt et al., 2014), there is new evidence of negative influences such as reduced sense of school belongingness and increased propensity to blame the victim - themselves. Interestingly, students who had a higher level of perceived discrimination also demonstrated a lower level of meritocracy belief. 
This combination of consequences not only harms college students directly, it also makes it more difficult for the students to seek help. Students who reported a perception of discrimination also admitted that their self-esteem was low and that their feelings of shame often prevented them from asking for help. Further, the students tended to feel less in control of their lives, and consequently, had little hope that asking for help would be effective or make improvements. These attitudes helped to promote feelings of discouragement and made them less likely to seek help from either their teachers or parents. Because of these attitudes, peer support may be a more effective way to cope with discrimination. However, the student's perception of discrimination also tended to reduce their sense of belonging - they felt less part of the school community, and therefore less connected with their peers. It was even worse for the peers who were similar to them as they were even more likely to engage in victim blame. Therefore, they were more likely to have negative feelings towards their peers within their own group.

There was also an association between perceptions of discrimination and a weaker belief in meritocracy, the belief that hard work leads to success despite the background of an individual. Therefore, a belief in meritocracy could be an effective self-coping tool for low status students. Overall, perceived discrimination is harmful to students in many ways, but it also keeps the student in a negative situation, and makes it more difficult for them to ask for help.

Students reported higher levels of perceived discrimination on individual levels than on group levels. Overall, less than 3\% of the students reported perceived discrimination on either a personal or group level. It is a positive point that such a small percentage of students feel they are discriminated against. However, perception of discrimination is still 
concerning, since there are 37 million students enrolled in college in China, amounting to a huge number of students who may suffer from discrimination. Therefore, it is imperative to have a self-coping tool for these students which can help to protect against discrimination.

A positive aspect of the findings is that students had a relatively high sensitivity towards prejudiced behavior directed towards them. The data also indicated three times more perceived prejudicial behavior from the students' professors than their peers. Conversely, the participants reported feeling that some of their professors were arrogant and insensitive. Female and post-graduate students tended to be more sensitive to perceived discriminatory behaviors and reported more such behavior from their professors. Although students from small towns perceived more discriminatory behavior from their professors, there was no difference reported among students from rural and urban areas or students from different levels of SES.

In summary, the information from this study helps us to better understand several important aspects regarding how Chinese college students perceive discrimination. First of all, only a small percentage of college students perceive discrimination, both personally and as a group, with the primary source being either because of differences in rural or urban background or lower SES. Besides lower SES, students were more likely to report perceived discrimination if before they attended college they had lived with a single mother or family member or if they lived with relatives other than their parents or grandparents.

Students who felt they were discriminated against were at greater risk of mental health issues due to lowered self-esteem, feeling less in control, a weakened sense of 
belongingness and lower belief in meritocracy. They were also more likely to blame other students who experienced discrimination (victim blame). The students seem to be very sensitive regarding perceptions of discrimination. However, they felt some of their professors were uncaring about the problem. In spite of these serious issues, there are limited resources that the students can or will access for support.

\section{Belief in Meritocracy as Protective Factor}

From this study, I can conclude that, yes, students' belief in meritocracy did positively support their psychological well-being. In addition, the protection effect was mediated by the students' perceived control. Students who strongly endorsed the belief in meritocracy had higher levels of self-esteem directly and indirectly via the mediator of perceived control. They also had a higher level of school belongingness fully mediated by perceived level of control.

Overall, a belief in meritocracy was found to benefit students and support their selfesteem and sense of school belongingness. This benefit is mainly mediated by a perception of self-control, with only a small loading left for direct effect between meritocracy belief and self-esteem. This benefit did not differ between male and female, rural and urban, or high and low SES groups. In other words, the belief in meritocracy benefited all students equally, despite whether they belonged to higher or lower status groups.

It is exciting to learn the belief in meritocracy was beneficial. In addition, the findings indicated that the majority of the students did not have a strong opinion regarding the belief in meritocracy, but tended to be more in the middle. However, students from high income families tended to have a stronger belief in meritocracy. The 
findings of this study are consistent with Yang and colleagues (2016) who hold that higher SES groups tend to endorse meritocracy belief more. Further, across students reporting a similar level of perceived discrimination, those who indicated a deeper belief in meritocracy also reported higher levels of self-esteem, sense of belonging to school and greater perception of control. Further, they were less likely to blame the victims for their perceptions of discrimination.

Findings in previous research (e.g. Foster et al., 2006; Major et al., 2007) indicated that discrimination interacts in the relationship between meritocracy belief and selfesteem - when the discrimination level was high, the belief in meritocracy was negatively associated with self-esteem. However when discrimination was low, meritocracy belief and self-esteem were positively correlated. Our finding supports this previous work, in that the overall discrimination level was low in Chinese colleges. However, in contrast to previous research, our study shows that the belief in meritocracy was negatively associated with victim blame (Major et al., 2007).

In addition, the positive correlation between meritocracy belief and school belongingness is a new finding. Furthermore, for students who perceived less discrimination (in this case, one standard deviation below the mean), the positive correlation between meritocracy belief and school belongingness was significant $(\mathrm{r}=$ $.222, p=.025, \mathrm{n}=102$ ). For those who reported more perceived discrimination (in this case, one standard deviation above the mean), the positive correlation between meritocracy belief and school belongingness was no longer significant $(\mathrm{r}=.130, p=.207$, $\mathrm{n}=96$ ). This indicated the level of discrimination influences the relationship between the belief in meritocracy and school belongingness. 


\section{Limitations and Directions for Future Research}

As in all research studies there were limitations to this work. First, I will discuss some limitations in the manner of participant recruitment. Next, much of the data were drawn from self-reported survey data. Third, the data were correlational, which can show important relationships between variables, but cannot show causality.

Recruitment. To recruit participants I asked teacher professors to distribute a QR code (Quick Response Code) in their classes. The code was distributed in basic psychology classes, with the exception of one computer science class. Since the psychology classes were not required for most majors in the universities, it is likely that the students enrolled in these classes may be more interested in psychology than the students in general. Further, participation in the survey was voluntary; therefore, it may be that the students who responded shared the further similar characteristic of heightened willingness to cooperate with or please their teachers.

Self-Reported Data. The data for this study are primarily collected through selfreport of the participants. This is a significant limitation of the study because lower status students may feel embarrassed about their situation, and therefore may choose to give socially acceptable responses, rather than their true feelings. Also, the wording of some of the questionnaire items are contrary to social norms. For example, one item which targets victim blame item states: "rural people get the negative stereotype because many of them act like that." Because of the social unacceptability of this statement the participants might choose not to express their true thoughts and feelings. Only one of the three universities in which students are surveyed agreed to provide academic information 
regarding the students, therefore, academic success will be measured by student selfreports and may be less than accurate.

Correlational Data. An important limitation of this research is the correlational data. Correlational data are valuable to show systematic relationships between different variables; however, it cannot demonstrate causality. Therefore, while the results can suggest that a belief in meritocracy protects students from being discriminated, they were correlational and I cannot infer causal relationship from the data. Similarly, results indicated perceived discrimination and belief in meritocracy influencing self-esteem, perception of control and sense of belonging. The data only provided correlational but not causal relationships.

Future studies should also consider investigating methods to provide more information in these important areas such as academic information which are essential to student well-being. Academic success is essential for student success and is likely to contribute heavily to a student's self-esteem and psychological well-being. In addition, a lower status student who is successful academically might perceive a lower level of discrimination due to his achievement, or more discrimination due to peer envy. On the other hand, low satisfaction with school life might lead to low academic performance. Therefore, the investigation of these interactions is important to future research.

By 2009 , approximately $20 \%$ of the college students were categorized as low SES, and $5 \sim 7 \%$ of the college students were recognized as needing financial aid. Besides low SES students who may face financial stress, other low status students suffered prejudice from their peers and from the society. For example, based on a survey conducted by the Chinese Academy of Social Sciences (CASS) in 2013, the unemployment rate of newly 
graduated rural college students was $30.5 \%, 18.2 \%$ higher than their urban peers; Wang (2009) pointed out that only $39.3 \%$ of newly graduated female students had job offers signed before graduation, whereas their male peers had a success rate of $46.9 \%$. Living under discrimination may shadow the daily life of lower status students leaving them vulnerable for physical and psychological disorders. Currently colleges offer limited amounts of financial aid and psychological counseling services. However, these aids and services will not cover all of the students who need help. Further, many lower status students feel ashamed by their situation and tend to avoid seeking help (Xie et al., 2016). Therefore, understanding the situation of discrimination and identifying a self-coping method to help support these students is extremely important.

This study provides important information regarding the perceptions of students in Chinese universities who are from different backgrounds and social statuses. If we can understand student perceptions, biases and fears, and therefore gather information regarding the issue of discrimination, more work can be done by improve the university environment and prevent some aspects of discrimination. If the belief in meritocracy is shown to protect lower status students, colleges can be guided as to what activities to emphasize, how to provide role models and what subjects should be focused on when teachers meet individually with their students. This may help students from all backgrounds to feel more comfortable at university, with a better sense of community and belonging, allowing them to focus more fully on their studies, and be more likely to be successful at university and in their future careers.

The variables which predicted belief in meritocracy seemed to be based on demographics or status. Therefore, how to support and increase the level of student 
meritocracy belief is an important matter for future research. Such support or interventions could greatly benefit students who perceive discrimination. Further research might focus on the point of how to practically increase students' belief in meritocracy. Such information could provide important ways for teachers, professors and social workers to support their students.

It's concerning that 3 times more perceived prejudicial behavior were reported from professors than from the student's peers. Since professors and teachers heavily influence students' life in colleges, it's important to take a deep look on why students had this impression of insensitivity.

To sum up, this study indicates that belief in meritocracy helps lower status students in Chinese universities who perceive discrimination. It also investigated the predictors and influences of the student's belief in meritocracy. The study illustrated the damage of perceived discrimination and identified some of the groups of vulnerable students who might be discriminated against. 


\section{APPENDIX}

\section{Appendix A, Survey questions (in English)}

Please choose the category that best describes you.

1. I am a/an student
a. Undergraduate
b. Graduate

2. I am a
a. Male
b. Female

1. My major is

2. My major belongs to the big category of
a. Literature
b. Engineer
c. Art and Science

1. I began college by the year of
a. 2018
b. 2017
c. 2016
d. 2015
e. 2014
f. 2013
g. others. Please discribe 
1. I came from the providence of

\begin{tabular}{|l|l|l|l|l|}
\hline A & B & C & F & G \\
a2. Aomen & b1. Beijing & c1. Chongqing & f1. Fujian & g1. Gansu \\
g2. Guangdong \\
g3. Guangxi
\end{tabular}


2. My hometown can be considered
a. Urban
b. Rural

3. Relatively, my hometown is in size
a. Large
b. Medium
c. Small

4. In my hometown, my household income can be considered
a. Far above average
b. Above average
c. Average
d. Under average
e. Far under average

5. Nationwidely, my household income can be considered
a. Far above average
b. Above average
c. Average
d. Under average
e. Far under average

6. My annual household income is approximately (in RMB)

7. When I was at home, I lived with
a. Both of my parents
b. My mom only 

c. My dad only
d. My grandparents
e. Other relatives

8. My dad's education level is
a. Under high school
b. High school graduate
c. Some college
d. College degree
e. Higher education

9. My mom's education level is
a. Under high school
b. High school graduate
c. Some college
d. College degree
e. Higher education

10. If I live with my grandparents or other relatives, their highest education level is/are
a. Under high school
b. High school graduate
c. Some college
d. College degree
e. Higher education

11. In all the close relatives that about my age or older, the rate of college enrollment 
is
a. Almost all of them attend(ed) college
b. Most of them attend(ed) college
c. About half of them attend(ed) college
d. Less than half of them attend(ed) college
e. Very few of them attend(ed) college

For the statement below, please tell us how much it is true for you.

Likert scale, 1 -- Strangly disagree 7 -- Strongly agree

1. It is some peasants fault that they received negative views

2. People from rural areas are prejudged because media exaggerated the negative aspect.

3. People from urban prejudge rural residence to make them look better

4. I have noticed some prejudicial behavior towards rural/poor/female students

5. People who feel that they are discriminated against are just oversensitive

6. Professors seem to discriminate against students depending on the region they are from.

7. My roommates talk as though they are prejudiced towards rural/poor/female people

8. My region group is discriminated against.

9. Students like me experience discrimination

10. I study harder compared to when I was in high school 11. I don't study as hard as my classmates

12. This college/university is the one that I originally wanted to enroll in 
13. This major is the one that I originally wanted to study

14. My parents/relatives are proud that I enrolled in college

15. Getting into a relationship is one of my goals in college

16. Any people who don't get ahead should not blame the system; they really only have themselves to blame.

17. If people work hard they almost always get what they want.

18. Even if people want to work hard, they don't always get ahead.

19. In China, getting ahead doesn't always depend on hard work.

20. I feel that China is an open society where all individuals can achieve a high status.

21. Advancement in China society is possible for all individuals.

22. Individual members in certain groups are often unable to advance in Chinese society.

23. Individual members of certain groups have difficulty achieving higher status.

24. I put as little effort into my college work as I can.

25. Many of the other students bother me.

26. I like working on projects with the students in my classes.

27. I feel proud of belonging to my college.

28. I am treated with as much respect as other students.

29. I feel very different from most other students here.

30. The teachers here respect me.

31. There's at least one teacher or other adult in this school I can talk to if I have a problem. 
32. Overall, I am satisfied about myself

33. At times I think I am not good at all

34. I feel that I have a number of good qualities

35. I am able to do things as well as most other people

36. I feel I do not have much to be proud of

37. I certainly feel useless at times

38. I feel that I am a person of worth, at least on an equal plane with others

39. I wish I could respect myself more

40. In general, I feel that I am a failure

41. I have a positive attitude about myself

42. I worry about whether others regard me as a success or failure

43. I feel self-conscious

44. I feel displeased with myself

45. I am worried about what other people think of me

46. I feel inferior to others at this moment

47. I am concerned about the impression I am making

48. I am worried about looking foolish

49. I have little control over the things that happen to me ;

50. There is really no way I can solve some of the problems I have;

51. There is little I can do to change many of the important things in my life ;

52. I often feel helpless in dealing with the problems of life

53. Sometimes I feel that I'm being pushed around in life

54. What happens to me in the future mostly depends on me 
55. I can do just about anything I really set my mind to do

56. On average, I study __ hours per day (besides classes)

57. I hope I could study ___ hours per day (besides classes)

58. My college entrance exam (CEE) score was

59. My GPA is

60. For the last final exam, I rank about percentile in my department.

61. For this semester, I think I will rank about percentile in my department.

62. I have a boyfriend/girlfriend (yes/no) 
Appendix B, Survey questions (in Chinese)

请选择最符合你的描述

1. 我是
a. 本科生
b. 研究生

1. 我是
a. 男生
b. 女生

1. 我的专业是

2. 我的专业属于-
a. 文科
b. 工科
c. 理科

1. 我的本科入学年份是一年
a. 2018
b. 2017
c. 2016
d. 2015
e. 2014
f. 2013
g. 其他, 请注明——

1. 我来自 


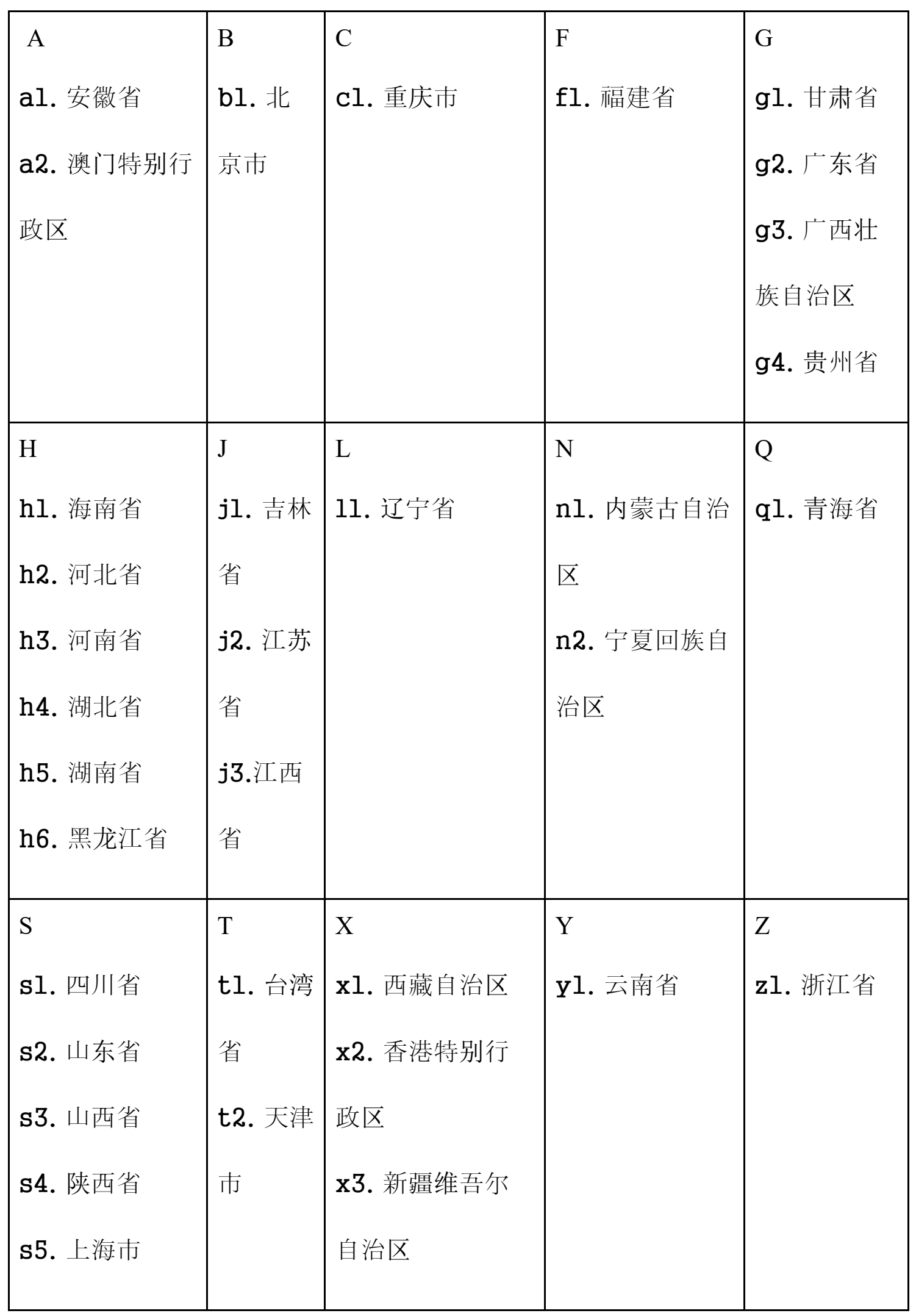


2. 我的家乡是一
a. 城市
b. 农村

3. 相对来说, 我的家乡是——城市(农村)
a. 大型
b. 中型
c. 小型

4. 和当地平均水平相比, 我的家庭属于
a. 富裕家庭
b. 中等偏上收入家庭
c. 本均收入水平家庭
d. 中等偏下收入家庭
e. 贫穷家庭

5. 和全国本均水本相比, 我的家庭属于
a. 富裕家庭
b. 中等偏上收入家庭
c. 平均收入水本家庭
d. 中等偏下收入家庭
e. 贫穷家庭

6. 我的家庭年收入大概是一 (元)

7. 我在家的时候, 跟一一同住 

a. 父母
b. 父
c. 母
d. (外) 祖父母
e. 其他亲戚

8. 我父亲的学历是一
a. 高中以下
b. 高中
c. 大专
d. 大本
e. 硕士及以上

9. 我母亲的学历是一
a. 高中以下
b. 高中
c. 大专
d. 大本
e. 硕士及以上

10. 如果我跟其他人同住, 他（们）的最高学历是一
a. 高中以下
b. 高中
c. 大专 

d. 大本
e. 硕士及以上

11. 在我比较亲近的同龄亲戚中,
a. 几乎每个都上过大学
b. 大部分都上过大学
c. 一半上过大学
d. 小部分上过大学
e. 几乎没人上大学

指导语 : 这个量表是用来了解您的大学生活和学习。请仔细阅读下面的句子, 选择最符合您情况的选项。请注意, 这里要回答的是您实际上认为您自己怎样, 而不是回答您认为您应该怎样。答案无正确与错误或好与坏之分, 请按照您的真 实情况来描述您自己。您的回答绝对不会向外泄漏, 因此您完全不必要有这方面的 顾虑。请您注意要保证每个问题都做了回答, 且只选一个答案。谢谢您的合作！

选项：请从1 7之间选择一个数字来表达您的符合情况。其中 1--- 非常不

符合 7-- 非常符合

1. 农民之所以受歧视有他们自身的原因

2. 农村人受歧视是因为媒体过分夸大了负面信息

3. 城里人嘲笑农村人不过是为了抬高自己

4. 我注意到有农村/贫困/女性学生受到过歧视

5. 觉得自己受歧视的人只不过是太敏感了 
6. 有些老师会基于地域/性别给予学生区别对待

7. 我从室友的言谈中感觉到他/她们对农村/贫困/女性有偏见

8. 我觉得受到了地域歧视

9. 像我一样的人受到了歧视

10. 我比上高中的时候用功

11. 我没有其他同学那么用功

12. 我现在读的学校是我理想中的学校

13. 我现在学的专业是我理想中的专业

14. 我的父母亲戚都很骄傲我上了大学

15. 交到男朋友/女朋友是我在大学要完成的事情之一

16. 中国是个开放社会, 所有人都能争取身份和地位

17. 当今社会, 所有人都能获得成功

18. 有些阶层的人怎么努力都难以取得成功

19. 有些人群就是无法得到身份和地位

20. 不能出人头地不要怪大环境, 主要是他们自己不努力

21. 只要努力, 就能达成目标

22. 就算有人很努力, 他们也无法成功

23. 功成名就有的时候跟努力没关系

24. 我在学校里完全不想努力

25. 不少同学让我心烦

26. 跟同学一起做项目很愉快 
27. 很骄傲成为学校的一员

28. 我跟同学们一样得到尊重

29. 我觉得与他人格格不入

30. 老师对我很好

31. 如果我遇到麻烦, 在学校里至少有一个老师或者成人可以和他/她谈谈

32. 总括而言, 我对自己感到满意

33. 有时候我认为自己是一无是处

34. 我觉得我有很多优点

35. 我做事的能力和大部份人一样好

36. 我觉得自己没有什么值得骄傲

37. 有时候我确实觉得自己很无用

38. 我认为自己是个有价值的人, 至少基本上是与别人相等的

39. 我希望我能够更多的尊重自己

40. 总括来说, 我觉得我是一个失败者

41. 我对于自己是抱着肯定的态度

42. 我在意别人认为我是成功者还是失败者

43. 我会聚焦在我自己身上

44. 我对自己不满意

45. 我在意别人对我的想法

46. 我觉得自己比别人差

47. 我在意自己给别人的印象 
48. 我担心自己看起来很俊

49. 我对发生在我身上的事情没有什么控制

50. 有些问题基本上我没办法解决

51. 人生关键的大事上我无能为力

52. 生活中的很多事情无法解决, 让人绝望

53. 我时常感觉到生活的恶意

54. 我的未来我做主

55. 只要我下定决心, 没有做不成的事情

56. 除了上课时间, 我平均每天学习多少小时

57. 我希望我能学习多少小时

58. 我的高考分数是

59. 我的GPA (学绩点) 是

60. 我上学期的期末成绩大概在年纪排名前百分之几?

61. 我估计这学期的期末成绩大概在年纪排名前百分之几?

62. 我有男/女朋友 $\bigcirc$ 是 $\bigcirc$ 否 


\section{Appendix C, Cover letter}

\section{Cover Letter}

You are being asked to take part in a research study of how college students perception of meritocracy affect their life and study. Please read this form carefully and ask any questions you may have before agreeing to take part in the study.

What the study is about: The purpose of this study is to learn how students with different beliefs of meritocracy affect their self-esteem, school belongings and thus influence their life and study.

What we will ask you to do: If you agree to be in this study, we will ask you to participant in an online survey. The survey will include questions about your perception of self-esteem, belongingness to school, your belief of meritocracy, and your academic performance. The survey will take about 10 15 minutes to complete.

\section{Risks and benefits:}

There is no any type of increased risk to you by participating this study. All of your responses to the survey will be anonymous. No one in your department or any of your teachers will know your answers. There are no benefits to you.

Compensation: You will have a unique code by the end of the survey to enter a lottery pool. Please print screen of the code. We will draw four 50 Yuan prepaid cell phone card from the lottery pool. You will be able to check the winning code list in 4 weeks after the survey. The confirmation code can be used to charge your cell phone at your convenience from taobao.com

Your answers will be confidential. The records of this study will be kept private. In any sort of report we make public we will not include any information that would make it possible to identify you. Research records will be kept in a locked file with password protection; only the researchers will have access to these records.

Taking part is voluntary: Taking part in this study is completely voluntary. You may skip any questions that you do not want to answer. If you decide not to take part or to skip some of the questions, it will not affect your grade score. If you decide to take part, you are free to withdraw at any time without any penalty. 
If you have questions: The researchers conducting this study are Xinting Zhao and Prof.Roberta Scholes. Please ask any questions you have now. If you have questions later, you may contact Xinting Zhao at xzgrb@mail.missouri.edu or at 573-639-9145. You can reach Prof. Scholes at ScholesR@missouri.edu. If you have any questions or concerns regarding your rights as a subject in this study, you may contact the Institutional Review Board (IRB) at

\author{
Campus Institutional Review Board \\ 483 McReynolds Hall \\ Columbia, MO 65211 \\ 573-882-9585 \\ E-Mail: umcresearchcirb@missouri.edu \\ Website: http://www.research.missouri.edu/cirb/index.htm
}




\section{Appendix D, IRB Approval Document}

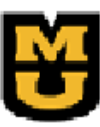

\author{
Institutional Review Board \\ University of Missouri-Columbia \\ FWA Number: 0002876 . \\ IRB Registration Numbers: 00000731, 00009014
}

\author{
482 McReynolds Hall \\ Columbia, MO 65211 \\ 573-882-3181 \\ irb@missouri_edu
}

December 04, 2018

Principal Investigator: Xinting Zhao (MU-Student)

Department: Educatnl \& Counslng Psych-PHD

Your IRB Application to project entitled Does the belief in meritocracy protect well-being of low status college students when percéeiving discriminationt? was reviewed and approved by the MU Institutional Review Board according to the terms and conditions described below:

$\begin{array}{ll}\text { IRB Project Number } & 2013169 \\ \text { IRB Review Number } & 243076 \\ \text { Initial Application Approval Date December 04, 2018 } \\ \text { IRB Expiration Date } & \text { December 04, 2019 } \\ \text { Level of Review } & \text { Exempt } \\ \text { Project Status } & \text { Active - Exempt } \\ \text { Exempt Categories } & 45 \text { CFR 46.101b(2) } \\ \text { Risk Level } & \text { Minimal Risk }\end{array}$

The principal investigator (PI) is responsible for all aspects and conduct of this study. The PI must comply with the following conditions of the approval:

1. No subjects may be inwolved in any study procedure prior to the IRB approval date or after the expiration date.

2. All changes must be IRB approved prior to implementation utilizing the Exempt Amendment Form.

3. The Annual Exempt Form must be submitted to the IRB for review and approval at least 30 days prior to the project expiration date to keep the study active or to close it.

4. Maintain all research réords for a periód of seven years from the project complétion daté.

If you have any questions, please contact the IRB at 573-882-3181 or irb@missouri.edu.

Thank you,

MU Institutional Review Board 


\section{BIBLIOGRAPHY}

Allen, K. A., \& Kern, M. L. (2017). School belonging in adolescents: theory, research and practice. Springer.

Allen, K., Kern, M. L., Vella-Brodrick, D., Hattie, J., \& Waters, L. (2016). What schools need to know about fostering school belonging: A meta-analysis. Educational Psychology Review, 1, 1-34

Benner, A. D., Crosnoe, R., \& Eccles, J. S. (2015). Schools, peers, and prejudice in adolescence. Journal of Research on Adolescence, 25(1), 173-188.

Benner, A. D., \& Graham, S. (2011). Latino adolescents' experiences of discrimination across the first 2 years of high school: Correlates and influences on educational outcomes. Child Development, 82(2), 508-519.

Brown-Iannuzzi, J. L., Adair, K. C., Payne, B. K., Richman, L. S., \& Fredrickson, B. L. (2014). Discrimination hurts, but mindfulness may help: Trait mindfulness moderates the relationship between perceived discrimination and depressive symptoms. Personality and Individual Differences, 56, 201-205.

Chinese Academy of Social Science (2013). Study on Employment, Living and Values of Chinese University Students. Beijing, China: Tsinghua University Press.

Chen, C. (2010). Current Situation of Impoverished College. Southwest Jiaotong: University Press.

Chen, Q. (2004). The relationship among coping style, social support, live pressure events and mental health of impoverished college students. Unpublished master's thesis, East China Normal University, Shanghai, China. 
Chen, Q. (2016). Relationship between psychological capital, coping style and mental health of impoverished undergraduate. Online Higher Education, 848, 109-109.

Chen, R., Qin, Z., Li, P., Zhao, Z., Chu, G., Yang, Y., Yao, Z., Yang, W., Chen, P., \& $\mathrm{Xu}, \mathrm{X}$. (2003). Study on psychological control and related factor in medical impoverished undergraduates. Health Psychology Journal, 11(5), 388-389.

Cattell, R. B., Eber, H. W., \& Tatsuoka, M. M. (1970). Handbook for the sixteen personality factor questionnaire (16 PF): In clinical, educational, industrial, and research psychology, for use with all forms of the test. Champaign, IL: Institute for Personality and Ability Testing.

Cheung, H. Y., \& Hui, S. K. F. (2003). Mainland immigrant and Hong Kong local students' psychological sense of school membership. Asia Pacific Education Review, 4(1), 67-74.

Cole, J. S., \& Gonyea, R. (2010). Accuracy of self-reported SAT and ACT test scores: Implications for research. Research in Higher Education, 51, 305-319.

Correia, I., Pereira, C. R., \& Vala, J. (2018). Under victimization by an outgroup: Belief in a just world, national identification, and ingroup blame. Frontiers in Psychology, 9, 1-11.

Costello, AB \& Osborne, Jason. (2005). Best Practices in Exploratory Factor Analysis: Four Recommendations for Getting the Most From Your Analysis. Practical Assessment, Research \& Evaluation, 10, 1-9.

Creel, H. G. (1964). The beginning of bureaucracy in china: the origin of the Hsien. Journal of Asian Studies, 23(2), 155-183. 
Darnon, C., Smeding, A., \& Redersdorff, S. (2017). Belief in school meritocracy as an ideological barrier to the promotion of equality. European Journal of Social Psychology, 48(4), 523-534.

Darnon, C., Wiederkehr, V., Dompnier, B., \& Martinot, D. (2018). 'Where there is a will, there is a way': Belief in school meritocracy and the social-class achievement gap. British Journal of Social Psychology, 57(1), 250-262.

Derogatis, L., Lipman, R., \& Covi, L. (1973). SCL-90. Psychopharmacol Bulletin, 9, 1328.

Freeman, T. M., Anderman, L. H., \& Jensen, J. M. (2007). Sense of belonging in college freshmen at the classroom and campus levels. The Journal of Experimental Education, 75(3), 203-220.

Foster, M. D., Sloto, L., \& Ruby, R. (2006). Responding to discrimination as a function of meritocracy beliefs and personal experiences: Testing the model of shattered assumptions. Group Processes \& Intergroup Relations, 9(3), 401-411.

Goodenow, C. (1993). The psychological sense of school membership among adolescents: Scale development and educational correlates. Psychology in the Schools, 30(1), 79-90.

Grubb, A., \& Turner, E. (2012). Attribution of blame in rape cases: A review of the impact of rape myth acceptance, gender role conformity and substance use on victim blaming. Aggression and Violent Behavior, 17(5), 443-452.

Guo, F., Zhao, L, \& Lian, Z. (2018). Reliability of self-reported data in college student engagement surveys: social desirability bias in self-reported survey. Journal of East China University, 4, 53-61. 
He, Z. (2011). Mental health and personality research on college students from rural area. Agricultural Archaeology, 3, 224-226.

Hambleton, R. K. (1996). Guidelines for adapting educational and psychological tests.

Han, X., \& Wu, J. (2018). The relationship between stress perception and subjective well-being of impoverished college students: The mediation of future sense of control. Think Tank Era, 146(30), 41-42.

Heatherton, T. F., \& Polivy, J. (1991). Development and validation of a scale for measuring state self-esteem. Journal of Personality and Social Psychology, 60(6), 895.

Inzlicht, M., McKay, L., \& Aronson, J. (2006). Stigma as ego depletion: How being the target of prejudice affects self-control. Psychological Science, 17(3), 262-269.

Jin, H. (2004). Attention on the phenomenon of the poor college students from the rural areas being discriminated against-thinking on Ma Jiajue's case. Journal of Shannix Institute of Junior Managerial Personnel, 17(3), 7-8.

Jost, J. T., \& Hunyady, O. (2002). The psychology of system justification and the palliative function of ideology. European Review of Social Psychology. 13, 111153.

Jost, J. T., Pelham, B. W., Sheldon, O., \& Sullivan, B. (2003). Social inequality and the reduction of ideological dissonance on behalf of the system: Evidence of enhanced system justification among the disadvantaged. European Journal of Social Psychology, 33, 13-36. 
Katz, I., \& Hass, R. G. (1988). Racial ambivalence and American value conflict: Correlational and priming studies of dual cognitive structures. Journal of Personality and Social Psychology, 55(6), 893.

Karcher, M. J., \& Lee, Y. (2002). Connectedness among Taiwanese middle school students: A validation study of the Hemingway measure of adolescent connectedness. Asia Pacific Education Review, 3(1), 92-114.

Karcher, M. J., \& Sass, D. (2010). A multicultural assessment of adolescent connectedness: Testing measurement invariance across gender and ethnicity. Journal of Counseling Psychology, 57 (3), 274-289.

Kong, D., Wang, X., \& Zhang, W. (2007). A study of the relationship between the selfesteem, self-control, general self-efficiency and subjective well-being of impoverished college students. Chinese Journal of Behavioral Medical Science, $16(1), 60-61$.

Krieger, N., Rowley, D. L., Herman, A. A., Avery, B., \& Phillips, M. T. (1993). Racism, sexism, and social class: implications for studies of health, disease, and wellbeing. American Journal of Preventive Medicine, 9(6), 82-122.

Kuncel, N. R., Credé, M., \& Thomas, L. L. (2005). The validity of self-reported grade point averages, class ranks, and test scores: A meta-analysis and review of the literature. Review of Educational Research, 75, 63-82.

Laurin, K., Fitzsimons, G. M., \& Kay, A. C. (2011). Social disadvantage and the selfregulatory function of justice beliefs. Journal of Personality and Social Psychology, 100(1), 149. 
Levin, S., Sidanius, J., Rabinowitz, J. L., \& Federico, C. (1998). Ethnic identity, legitimizing ideologies, and social status: A matter of ideological asymmetry. Political Psychology, 19(2), 373-404.

Li, Y. (2002). Mental health status and coping style of impoverished undergraduates. Chinese Journal of Health Education, 118(19), 566-567.

Liu S. \& Zhou, Q. (1995). Description of management efficiency of funding for education in rural schools. Education and Management, 6.

Loeb, E, \& Hurd, N.M. (2017). Subjective social status, perceived academic competence, and academic achievement among underrepresented students. Journal of College Student Retention: Research, Theory, \& Practice, 0 (0), 1-16.

Long, X. (2003). Cause analysis and countermeasures on mental health of poor college students. Higher Education Research, 5, 90-93.

Ma, Y., \& Wang, Y. (2006). A perspective of china's education from the phenomenon of Ma Jia Jue. Journal of Hainan Radio and TV University, 24(3).

Major, B. (1994). From social inequality to personal entitlement: The role of social comparisons, legitimacy appraisals, and group membership. In M. P. Zanna (Ed.), Advances in experimental social psychology, 26, 293-355.

Major, B., Gramzow, R. H., McCoy, S. K., Levin, S., Schmader, T., \& Sidanius, J. (2002). Perceiving personal discrimination: the role of group status and legitimizing ideology. Journal of Personality and Social Psychology, 82(3), 269282. 
Major, B., Kaiser, C. R., \& McCoy, S. K. (2003). It's not my fault: When and why attributions to prejudice protect self-esteem. Personality and Social Psychology Bulletin, 29(6), 772-781.

Major, B., Kaiser, C. R., O’Brien, L. T. \& McCoy, S. K. (2007). Perceived discrimination as worldview threat or worldview confirmation: Implications for self-esteem. Journal of Personality and Social Psychology, 92(6), 1068-1086.

Major, B., Kaiser, C. R., O’Brien, L. T. \& McCoy, S. K. (2013). Is the belief in meritocracy palliative for members of low status groups? Evidence for a benefit for self-esteem and physical health via perceived control. European Journal of Social Psychology. 43(4). 307-318.

Major, B., \& O’Brien, L. T. (2005). The social psychology of stigma. Annual Review of Psychology, 56, 393-421.

McCoy, S. K., Wellman, J. D., Cosley, B., Saslow, L., \& Epel, E. (2013). Is the belief in meritocracy palliative for members of low status groups? Evidence for a benefit for self-esteem and physical health via perceived control. European Journal of Social Psychology, 43(4), 307-318.

Mendes, W. B., McCoy, S., Major, B., \& Blascovich, J. (2008). How attributional ambiguity shapes physiological and emotional responses to social rejection and acceptance. Journal of Personality and Social Psychology, 94(2), 278-291.

Mossakowski, K. N. (2003). Coping with perceived discrimination: Does ethnic identity protect mental health? Journal of Health and Social Behavior, 318-331.

Naylor, J. C., Pritchard, R. D., \& Ilgen, D. R. (2013). A theory of behavior in organizations. Academic Press. 
Noh, S., \& Kaspar, V. (2003). Perceived discrimination and depression: Moderating effects of coping, acculturation, and ethnic support. American Journal of Public Health, 93(2), 232-238.

O’Brien, L. T., \& Major, B. (2005). System-justifying beliefs and psychological wellbeing: The roles of group status and identity. Personality and Social Psychology Bulletin, 31(12), 1718-1729.

Pan, Q. \& Zhou, Z. (2009). Relationship between psychological capital, coping style and mental health of impoverished college students. Chinese Journal of Health Psychology, 17(7), 844-846.

Pang, Y. C. (2015). The relationship between perceived discrimination, economic pressure, depressive symptoms, and educational attainment of ethnic minority emerging adults: the moderating role of school connectedness during adolescence (Doctoral dissertation, Iowa State University).

Pascoe, E. A., \& SmartRichman, L. (2009). Perceived discrimination and health: A metaanalytic review. Psychological Bulletin, 135(4), 531-554.

Pearlin, L. I., \& Schooler, C. (1978). The structure of coping. Journal of Health and Social Behavior, 2-21.

Pittman, L. D., \& Richmond, A. (2007). Academic and psychological functioning in late adolescence: The importance of school belonging. The Journal of Experimental Education, 75(4), 270-290.

Plaut V. C., Markus H. R. , \& Lachman M. E. (2002). Place matters: Consensual features and regional variation in American well-being and self. Journal of Personality and Social Psychology, 83, 160-184. 
Qi, Y. (2005). Mental health comparison between rural and urban college student. China Journal of Public Health Management, 21(4), 333-334.

Qian, X., \& Smyth, R. (2005). Measuring regional inequality of education in China: Widening coast-inland gap or widening rural-urban gap? Paper presented the ABERU Discussion Papers, Monash University, Australia. Report of the fourth meeting of the Eleventh National People's Congress. (2007).

Reynolds, J. \& Xian, H. (2014). Perceptions of meritocracy in the land of opportunity. Research in Social Stratification and Mobility, 36, 121-137.

Rosenberg, M. (2015). Society and the adolescent self-image. Princeton, US: Princeton University Press.

Sealy, R. (2010). Changing perceptions of meritocracy in senior women's careers, Gender in Management: An International Journal, 25(3), 184-197.

Schmader, T., Major, B., \& Gramzow, R. H. (2001). Coping with ethnic stereotypes in the academic domain: Perceived injustice and psychological disengagement. Journal of Social Issues, 57(1), 93-111.

Schmitt, M. T., Branscombe, N. R., Postmes, T., \& Garcia, A. (2014). The consequences of perceived discrimination for psychological well-being: a meta-analytic review. Psychological Bulletin, 140(4), 921.

Simpson, G. E. , \& Yinger, J. M. (2013). Racial and cultural minorities: An analysis of prejudice and discrimination. Causes and consequences of prejudice and discrimination. Springer Science \& Business Media. 
Smart Richman, L., \& Leary, M. R. (2009). Reactions to discrimination, stigmatization, ostracism, and other forms of interpersonal rejection: A multimotive model. Psychological Review, 116(2), 365-395.

Smith, J. F. \& Skrbiš, Z. (2017). A social inequality of motivation? The relationship between beliefs about academic success and young people's educational attainment. British Educational Research Journal, 43(3), 441-465.

Son Hing, L. S., Bobocel, D. R. \& Zanna, M. P. (2002). Meritocracy and opposition to affirmative action: making concessions in the face of discrimination. Journal of Personality and Social Psychology, 83(3), 493-509.

State Education Commission report on the reform of the distribution system of college graduates. (1996).

Stevens, J. P. (2002). Applied multivariate statistics for the social sciences, Mahwah, New Jersey: Lawrence Erlbaum Associates.

Sun, J. \& Zang, J. (2015). Survey on psychological poverty problem among college poverty students. Chinese Journal of Health Education, 31(3), 334-335.

Townsend, S. S., Major, B., Sawyer, P. J., \& Mendes, W. B. (2010). Can the absence of prejudice be more threatening than its presence? It depends on one's worldview. Journal of Personality and Social Psychology, 99, 933-947.

Van de Vijver, F., \& Hambleton, R. K. (1996). Translating tests. European Psychologist, 1(2), 89-99.

Wang, C. (2012). Farmers in the process of urbanization. Modern Agriculture, 5.

Wang, W. (2011). 1148 Vocational students' mental health status survey and analysis. Vocational Education, 1. 
Wang, Y. \& D., Y. (2006). Solutions to improve mental health of poor college students. Teaching and Managing, 12.

Wang, Z. (2009). Status quo, causes and legal countermeasures of female college students' employment discrimination. Journal of Ocean University of China, 4, 90-93.

Wiederkehr, V., Bonnot, V., Krauth-Gruber, S., \& Darnon, C. (2015). Belief in school meritocracy as a system-justifying tool for low status students. Frontiers in Psychology, 6.

Williams, D. R., \& Collins, C. (1995). US socioeconomic and racial differences in health: Patterns and explanations. Annual Review of Sociology, 21, 349-386.

Williams, D. R., \& Mohammed, S. A. (2009). Discrimination and racial disparities in health: evidence and needed research. Journal of Behavioral Medicine, 32(1), 2047.

Wu, G. (2009). Why 840,000 rural students gave up in CEE. Modern Parents, 10.

$\mathrm{Wu}, \mathrm{J}$. (2016). The proportion of college counselors is still low and more willing to silently bear. The Paper.

Wu, Z., Ma, J., \& Qi, M. (2012). Psychological analysis and aid policy about college students with economic difficulties. College Instructors, 14(3), 53-56.

Xiao, D. (2014). Research on the situation and relationship of frustration tolerance and coping style to poor college students. Science of Social Psychology, 29(8), 43-46.

Xin, Z., Zhang, M., \& He, M. (2012). Changes in college students' mental health: a crosstemporal meta-analysis. Acta Psychologica Sinica, 44(5), 664-679. 
Xie, Q., Wan, J., Zhang, R., \& Jiang, J. (2016). Perceived discrimination and loneliness among the rural impoverished college students: the mediating effect of core selfevaluation and friends-support. Psychological Development and Education, $32(5), 614-622$.

Xu, R. (2001). Psychological education on mental health of impoverished undergraduate. Chinese Mental Health Journal, 15(4), 284-285.

Xue, Z., LU, L., \& Liang, Z. (2008). Investigation on mental health state of university students from countryside. China Public Health, 24(8).

Yang, Q. (2004). Reasons and solutions of psychological problems of poor college students. Journal of Leshan Teachers College, 19(10).

Zhang, H. \& Xie, Q. (2009). Investigation of college students' beliefs about psychological counseling. Culture, 3(7), 214-216.

Zhang, J., Li, X., Fang, X. \& Xiong, Q. (2009). Discrimination experience and quality of life among rural-to-urban migrants in China: the mediation effect of expectationreality discrepancy. Quality of Life Research, 18(3), 291-300.

Zhang, J., Zheng, M., Su, X., Li, J., \& Ye, X. (2005). Effect of social support on the changes of self-esteem in patients with colostomy. Chinese Journal of Nursing, 40(7), 489-492.

Zhang, J., Ban, Y., \& Yin, H. (2011). Relationship between mental health and social support coping style among poor college students in less developed regions. China Journal of Health Psychology, 19(7), 868-869.

Zhang, Y. (2004). Mental health state of 1496 college students. China Journal of Public Health, 20(12), 1523-1524. 
Zhang, Z. (2015). Crowding out meritocracy? Cultural constraints in Chinese public human resource management. Australian Journal of Public Administration, 74(3), $270-282$.

Zheng, S. (2008). A meta-analysis review on mental health of impoverished undergraduates. Journal of Liaoning Economic Management Cadre Institute, 4, 105-106. 


\section{VITA}

Xinting Zhao was born in Shandong province in China. When she went to college, she perceived discrimination because of her accent. Then she entered graduate school, worked as a research assistant in Labs of Psychology Measurements and Scales where she noticed some psychological measurements were not well localized. The concern of scales' reliability and validity motivated her to pursue a doctoral degree in educational psychology, specifically in Statistics, Measurement \& Evaluation in Education. 